\title{
Evaluation of the Weather Research and Forecast/Urban Model Over Greater Paris
}

\author{
Youngseob Kim • Karine Sartelet • Jean-Christophe Raut • \\ Patrick Chazette
}

Received: 6 July 2012 / Accepted: 4 July 2013 / Published online: 27 July 2013

(C) The Author(s) 2013. This article is published with open access at Springerlink.com

\begin{abstract}
Meteorological modelling in the planetary boundary layer (PBL) over Greater Paris is performed using the Weather Research and Forecast (WRF) numerical model. The simulated meteorological fields are evaluated by comparison with mean diurnal observational data or mean vertical profiles of temperature, wind speed, humidity and boundary-layer height from 6 to 27 May 2005. Different PBL schemes, which parametrize the atmospheric turbulence in the PBL using different turbulence closure schemes, may be used in the WRF model. The sensitivity of the results to four PBL schemes (two non-local closure schemes and two local closure schemes) is estimated. Uncertainties in the PBL schemes are compared to the influence of the urban canopy model (UCM) and the updated Coordination of Information on the Environment (CORINE) land-use data. Using the UCM and the CORINE land-use data produces more realistic modelled meteorological fields. The wind speed, which is overestimated in the simulations without the UCM, is improved below 1,000 $\mathrm{m}$ height. Furthermore, the modelled PBL heights during nighttime are strongly modified, with an increase that may be as high as $200 \%$. At night, the impact of changing the PBL scheme is lower than the impact of using the UCM and the CORINE land-use data.
\end{abstract}

Keywords CORINE land-use $\cdot$ Planetary boundary layer · Urban canopy model · Weather Research and Forecast model

Y. Kim $(\bowtie) \cdot$ K. Sartelet

CEREA, Joint Research Laboratory, École des Ponts ParisTech/EDF R\&D, Université Paris-Est, 6-8 Avenue Blaise Pascal, Cité Descartes, Champs-sur-Marne, 77455 Marne la Vallée Cedex 2, France e-mail: kimy@cerea.enpc.fr

J.-C. Raut

Laboratoire Atmosphères Milieux Observations Spatiales (LATMOS), Laboratoire Mixte UPMC-UVSQ-CNRS, UMR 8190, Université Paris 6, 4 Place Jussieu, 75252 Paris, France

P. Chazette

Laboratoire des Sciences du Climat et de l'Environnement (LSCE), Laboratoire Mixte

CEA-CNRS-UVSQ, CEA Saclay, 91191 Gif-sur-Yvette, France 


\section{Introduction}

The vertical dispersion of atmospheric pollutants in the planetary boundary layer (PBL) is mostly governed by motions caused by turbulence. For the vertical dispersion, the temperature stratification plays an important role in defining the atmospheric stability, the intensity of thermal turbulence and the depth of the boundary layer. These factors regulate the upward dispersion of pollutants and the rate of replacement of cleaner air from above (Oke 1987).

Numerical experiments have been carried out to accurately depict the vertical atmospheric motion. Explicitly resolving the turbulent motions in the PBL has been limited to idealized physical conditions (Moeng et al. 2007). Therefore parametrizations are generally used for PBL modelling (e.g. Pleim and Chang 1992; Holtslag et al. 1995; Hong and Pan 1996; Hong et al. 2006; Hourdin et al. 2006; Pleim 2007; Nakanishi and Niino 2009) in numerical weather prediction systems such as the Fifth generation Penn State/NCAR Mesoscale Model (MM5) or the Weather Research and Forecast (WRF) model. These parametrizations of turbulent fluxes in the PBL using turbulence closure schemes are referred to as PBL schemes.

The PBL schemes have been evaluated and intercompared for boundary-layer modelling in the U.S.A. (Berg and Zhong 2005; Olson and Brown 2009; Hu et al. 2010; Kim et al. 2010; Shin and Hong 2011), Asia (Srinivas et al. 2007; Han et al. 2008) and Europe (Borge et al. 2008). However there has been no intercomparison study at urban scales using the WRF model and an urban canopy model (UCM).

Meteorological fields for urban areas differ from those for surrounding rural areas because of different geometry (radiation trapping and wind profiles) and materials (heat storage) of their surfaces and different energy consumption (heat release). For accurate modelling of urban meteorological fields, we need the appropriate land-use data (location of urbanized areas and their fraction in a grid cell) and an urban model that describes heat/momentum exchange between urban structures and the lower atmosphere. For example, the impact of land-use data on temperature in the lower atmosphere was studied using WRF/UCM over the Phoenix metropolitan area in the U.S.A. by Grossman-Clarke et al. (2010) and over northern Taiwan by Lin et al. (2008).

The impacts of urban models on the meteorological fields in the lower atmosphere have been studied over a range of large cities (e.g., Kusaka and Kimura 2004; Otte et al. 2004; Dandou et al. 2005; Lin et al. 2008; Miao et al. 2009; Grossman-Clarke et al. 2010; Lee et al. 2010; Flagg and Taylor 2011; Salamanca et al. 2011). In particular, the WRF/UCM have been used for different studies. For example, Miao et al. (2009) found that the diurnal cycle of urban heat intensity was well reproduced by the WRF/urban model in Beijing, China. Lee et al. (2010) suggested that proper surface representation and explicit parametrizations of urban physical processes are required for accurate urban modelling in Houston, U.S.A. Flagg and Taylor (2011) examined the sensitivity of the surface energy balance, canopy layer and boundary-layer processes on the scale of urban surface representation. They found that small changes in the scale can affect the urban fraction used in the surface representation, affecting meteorological fields (e.g., surface heat flux and skin surface temperature) in Detroit, U.S.A.-Windsor (Canada) area. Salamanca et al. (2011) conducted simulations with high resolution urban canopy parameters in Houston, and revealed that a simple bulk urban scheme is sufficient for an estimate of the 2-m temperature in an urban area. However a complex urban canopy scheme and a high resolution urban canopy parameter database (e.g., urban fraction, building height and building area) are necessary for an evaluation of the urban heat intensity or the energy consumption due to air conditioning.

The anthropogenic heat release is an important variable for accurate modelling of air temperature over urban areas. However it is difficult to estimate representative values for 
urban areas. The effect of the anthropogenic heat release has been studied by Dupont et al. (2004); Sailor and Lu (2004) and Fan and Sailor (2005) over the U.S.A. and by Sarrat et al. (2006); Pigeon et al. (2007) and Sarkar and De Ridder (2011) over France. Allen et al. (2011) developed a model to estimate anthropogenic heat flux from global to individual city scales. In this model, three anthropogenic heat sources (metabolic heat, traffic heat and building heat) are estimated for a global scale $\left(0.50^{\circ}\right.$ grid resolution) and individual city scales.

The PBL schemes are attached to large uncertainties, which have a large impact not only on meteorology but also on air quality modelling (Mallet and Sportisse 2006; Roustan et al. 2010). The impact of urban canopy models on air quality modelling is also widely recognized (e.g., Lemonsu and Masson 2002 and Chen et al. 2011). However, UCM have not been widely used when modelling air quality over Paris and its suburbs (hereafter Greater Paris) (Tombette and Sportisse 2007; Vautard et al. 2007; Korsakissok and Mallet 2010; Sciare et al. 2010; Roustan et al. 2011; Royer et al. 2011).

This paper aims at evaluating the relative impact of the PBL scheme used in the WRF model and the use of an UCM over Greater Paris. The WRF/urban model is evaluated over Greater Paris during May 2005. The model is compared to in-situ measurements of temperature, wind speed and humidity at a ground station (Palaiseau), a tall mast (Saclay), a radiosonde station (Trappes), and an observation deck at a height of $319 \mathrm{~m}$ on the Eiffel Tower (Paris). Furthermore, mobile lidar data from the LISAIR (LIdar pour la Surveillance de l'AIR, Raut and Chazette 2009) campaign are used to estimate PBL height. The paper is organized as follows: first, the settings of the WRF model used here are described. Second, meteorological measurements used for comparisons to modelled results are detailed, and then the different methods used for estimation of PBL heights are briefly presented. Fourthly, a sensitivity study of meteorological data to the PBL schemes is performed, as well as to UCMs and land-use data. Finally, the relative sensitivity of the meteorological fields to the PBL schemes and to the UCMs and land-use data is discussed.

\section{The Weather Research and Forecast (WRF) Model}

The WRF model version 3.3 with the Advanced Research WRF (ARW) dynamics solver is used to obtain meteorological fields over Greater Paris (Skamarock et al. 2008).

\subsection{Simulation Settings}

The regular latitude-longitude map projection is used for three simulation domains with two-way nesting. The horizontal grid spacing of the coarse domain is $0.5^{\circ}$, and $0.125^{\circ}$ and $0.03125^{\circ}$, respectively, for the two nested domains. The largest $0.5^{\circ}$ domain covers Europe and the smallest domain covers Greater Paris. The U.S. Geological Survey (USGS) Global Land Cover Characteristics (GLCC) database is used (10-arc minute, 2-arc minute and 30-arc second land-use data for the three domains, respectively). There are 28 vertical levels refined near the surface and the pressure at the model top is $100 \mathrm{hPa}$. The physical parametrizations used include the Kessler microphysics scheme (Kessler 1969), the RRTM longwave radiation scheme (Mlawer et al. 1997), the Goddard shortwave scheme (Chou and Suarez 1994), the Grell-Devenyi ensemble cumulus parametrization scheme (Grell and Devenyi 2002) and the Noah land-surface model (Chen and Dudhia 2001). The National Centers for Environmental Prediction (NCEP) final (FNL) operational model global tropospheric analyses are used for 
the initial and boundary conditions. The NCEP FNL analyses are available on a $1.0^{\circ} \times 1.0^{\circ}$ grid every $6 \mathrm{~h}$. The three-dimensional analysis nudging method of the NCEP analyses is used in the WRF model. The simulations are carried out for three weeks from 6 May to 27 May 2005, and simulation results are saved every $30 \mathrm{~min}$ for the finer grid simulations.

\subsection{Planetary Boundary-Layer Schemes}

Numerical PBL schemes have been developed to apply various parametrizations in the WRF model. We evaluate here four PBL schemes that are currently operational in the WRF model; brief descriptions are given below.

The Yonsei University (YSU) scheme (Hong et al. 2006) is a revised Medium-Range Forecast (MRF) scheme (Hong and Pan 1996); the YSU scheme is a non-local closure scheme. In the YSU and MRF schemes, a counter-gradient term is incorporated for the non-local closure. This term is a correction to the local gradient of heat and water vapour, and incorporates the contribution of the large-scale eddies to the total flux in the PBL under unstable conditions (Hong and Pan 1996).

The second scheme, ACM2 is the new version of the Asymmetric Convective Model (ACM) scheme (Pleim 2007); the ACM2 scheme is also a non-local closure scheme. In the ACM schemes, the non-local nature is represented by using a transilient term that defines the mass flux between any pair of model layers even if they are not adjacent (Pleim and Chang 1992). The ACM2 scheme adds an eddy diffusion component to the transilient term of the original ACM scheme.

The Mellor-Yamada-Janjic (MYJ) scheme (Janjić 2001) is a local closure scheme. The MYJ scheme determines eddy diffusivities from prognostically calculated turbulent kinetic energy (TKE) (Hu et al. 2010). The Mellor-Yamada-Nakanishi and Niino (MYNN) level-2.5 scheme (Nakanishi and Niino 2004) is also a TKE-based scheme. The MYNN scheme and the MYJ scheme are developed to improve performances of the original Mellor-Yamada model (Mellor and Yamada 1974). Major differences between the two schemes include formulations for mixing length and methods to determine unknown parameters. The MYJ scheme uses observations to determine unknown parameters while the MYNN scheme uses large-eddy simulation (LES) results. Olson and Brown (2009) highlighted the differences between the MYJ and the MYNN schemes. The MYNN scheme produces larger TKE and mixing length, which lead to slightly greater mixed-layer depths in the MYNN scheme than in the MYJ scheme.

Hu et al. (2010) showed that the ACM2 and the YSU schemes predicted stronger vertical mixing than the MYJ scheme in the lower atmosphere. This produced stronger entrainment at the top of the PBL and, in turn, produced a warmer and drier lower atmosphere. However, Shin and Hong (2011) compared the vertical profiles of diffusivities with the PBL schemes and showed that the vertical mixing in the MYJ scheme was stronger than the ACM2 and the YSU schemes during daytime. They also revealed that discrepancies between state-of-the-art PBL schemes are important in modelling surface variables under stable conditions.

In the framework of the Global Energy and Water Exchange Project (GEWEX) Atmospheric Boundary Layer Study (GABLS) intercomparisons, Svensson et al. (2011) presented comparisons of single-column models including the ACM2, the YSU and the MYJ schemes. The vertical profiles of the potential temperature during daytime were significantly different between the PBL schemes: neutral profiles for both the ACM2 and the YSU schemes and typical unstable profiles for the MYJ scheme. 


\subsection{Surface-Layer Schemes}

Parametrizations of turbulence near the surface using the Monin-Obukov similarity theory are referred to as surface-layer schemes. In the current version of the WRF model, surfacelayer schemes are linked to particular PBL schemes. This can be a source of discrepancies between simulations conducted with different PBL schemes. The used surface-layer schemes linked to PBL schemes are: the MM5 similarity scheme (Zhang and Anthes 1982) to the YSU scheme, the Pleim-Xiu scheme (Pleim 2006) to the ACM2 scheme, the Eta similarity scheme (Janjić 1990) to the MYJ scheme, and the MYNN surface-layer scheme to the MYNN PBL scheme.

\subsection{Urban Surface Models}

To consider the effects of urbanization, the WRF model includes three urban surface models: the UCM (Kusaka et al. 2001), the Building Environment Parametrization (BEP) (Martilli et al. 2002) and the Building Energy Model (BEM) (Salamanca et al. 2010). The UCM is a simple single-layer model, while the BEP and the BEM models are multi-layer models. Urban models are used to represent the influence of urbanization on the surface temperature. Kusaka et al. (2001) showed that the diurnal variations of surface temperature from the UCM are close to those from the multi-layer models. In addition, the UCM includes the anthropogenic heat release in the total sensible heat flux. It is not explicitly represented in the multi-layer models. Therefore the UCM is used for this study. If an urban surface model is not used, the WRF model uses the NOAH land-surface model, which distinguishes urban from non-urban areas by differences in vegetation parameters (surface albedo, roughness length, green vegetation fraction). However, it does not take into account the effect of geometric (building height, building width, road width) and thermal parameters (anthropogenic heat, thermal conductivities, heat capacity).

Geometric and thermal parameters for the UCM have a significant effect on the transfer of energy and momentum between the urban surface and the atmosphere (Loridan et al. 2010; Wang et al. 2011; Loridan and Grimmond 2012). The parameters used in this study are summarized in Table 1; most parameters are based on Kusaka et al. (2001). Although the

Table 1 Geometric and thermal parameters for the urban canopy model

\begin{tabular}{ll}
\hline Parameter & Value \\
\hline Building height & $12 \mathrm{~m}$ \\
Roof width & $3.75 \mathrm{~m}$ \\
Road width & $11.25 \mathrm{~m}$ \\
Urban area ratio for a grid & 0.95 \\
$\quad$ Vegetation area ratio for a grid & 0.05 \\
$\quad \begin{array}{l}\text { Diurnal maximum of anthropogenic } \\
\text { heat flux }\end{array}$ & $70 \mathrm{~W} \mathrm{~m}^{-2}$ \\
$\begin{array}{l}\text { Diurnal profile of anthropogenic heat } \\
\quad \text { flux }\end{array}$ & See Fig. 1 \\
$\begin{array}{l}\text { Surface albedo of roof, road and wall } \\
\text { Surface emissivity of roof, road and wall }\end{array}$ & 0.20 \\
$\quad \begin{array}{l}\text { Volumetric heat capacity of roof, } \\
\quad \text { road and wall }\end{array}$ & 0.97 \\
Thermal conductivity of roof, road and wall & $2.01 \times 10^{6} \mathrm{~J} \mathrm{~m}^{-3} \mathrm{~K}^{-1}$ \\
\hline
\end{tabular}


choice of the parameters is important, it is sometimes difficult to choose representative values for a city. Temperature and wind speed are very sensitive to the ratio of the building width to the road width, which is chosen using repeated model-to-measurement tests. The optimized ratio for this study is 0.33 . Using a single set of parameters over the whole urban area is not realistic; however there is only one urban category in the land-use data used herein. In future studies, adding sub-urban categories in the land-use data would make the urban model more realistic.

The anthropogenic heat release $\left(Q_{\mathrm{F}}\right)$ is likely to have a very strong impact on the modelled sensible heat flux, in particular, during nighttime and hence on the PBL processes due to enhanced urban turbulence (Stull 1988). The $Q_{\mathrm{F}}$ value for Paris is based on the work of Allen et al. (2011) who compute $Q_{\mathrm{F}}$ for different cities around the world. They presented annual mean and annual maximum $Q_{\mathrm{F}}$ based on hourly values. Tokyo and New York have the highest annual mean $Q_{\mathrm{F}}$ (around $60 \mathrm{~W} \mathrm{~m}^{-2}$ ). Although the annual mean $Q_{\mathrm{F}}$ is not specified for Paris in Allen et al. (2011), the annual maximum $Q_{\mathrm{F}}$ for Paris $\left(261 \mathrm{~W} \mathrm{~m}^{-2}\right)$ is between the values for New York $\left(550 \mathrm{~W} \mathrm{~m}^{-2}\right)$ and Tokyo $\left(180 \mathrm{~W} \mathrm{~m}^{-2}\right)$. The ratio between the annual maximum $Q_{\mathrm{F}}$ and the annual mean $Q_{\mathrm{F}}$ varies from one city to another; the ratio is about 3 for Tokyo, 5 for London and as high as 10 for New York. Assuming a ratio of 4 for Paris leads to an annual mean $Q_{\mathrm{F}}$ of about $65 \mathrm{~W} \mathrm{~m}^{-2}$, which is similar to Tokyo and New York. The $Q_{\mathrm{F}}$ in May is estimated from the annual mean $Q_{\mathrm{F}}$ based on the work of Pigeon et al. (2007) and Allen et al. (2011). They estimated the ratio between the annual $Q_{\mathrm{F}}$ and the $Q_{\mathrm{F}}$ in May to be 1.15 for Toulouse and 1.25 for London, respectively. The ratio for Paris is assumed to be 1.2 in this study. The diurnal variation of $Q_{\mathrm{F}}$ in May is computed based on the diurnal cycle in the local emission inventory for human activities obtained from Airparif (http://www.airparif.asso.fr/en/index/index). Note that the morning and evening energy consumption peaks do not appear in this profile of total anthropogenic heat, which includes metabolic heat, traffic heat and building heat. The morning and evening energy consumption peaks are mostly due to the traffic heat during working days, and the contribution of the traffic heat to the total anthropogenic heat may vary from 25 to $62 \%$ (Allen et al. 2011). The contribution of traffic emissions may also be underestimated in the local emission inventory used in this study. Figure 1 presents the diurnal variation of $Q_{\mathrm{F}}$ for Paris in May.

The USGS land-use data are commonly used in the WRF model. However, this database was created in 1993 and the land-use changes between 1993 and 2005 are important over Greater Paris according to the database of the European Environment Agency (EEA). Therefore, the recent Coordination of Information on the Environment (CORINE) land-use data of EEA is used instead of the USGS data. In order to use the CORINE landuse data in the WRF simulations, the land-use categories of the CORINE land-use data were converted to the categories of the USGS data following Pineda et al. (2004). The geographical coordinate system of the CORINE land-use data, European Terrestrial Reference System 1989 (ETRS89)—Lambert Azimuthal Equal Area (LAEA) is not directly usable in the WRF model. Thus the reprojection of the coordinate system to World Geodetic System 1984 (WGS84) was carried out following Arnold et al. (2010). The CORINE land-cover 2006 raster data (version 13) with a resolution of $250 \mathrm{~m}$, which are freely available at http://www.eea.europa.eu/data-and-maps/data/corine-land-cover-2006-raster, were used for this study. Figure 2 displays the changes of dominant land-use category from the USGS data to the CORINE data. The category for urban and built-up land (category 1) is dominant in Paris in both the USGS and the CORINE data but the category 1 area is extended southwards and westwards from Paris in the CORINE data. 


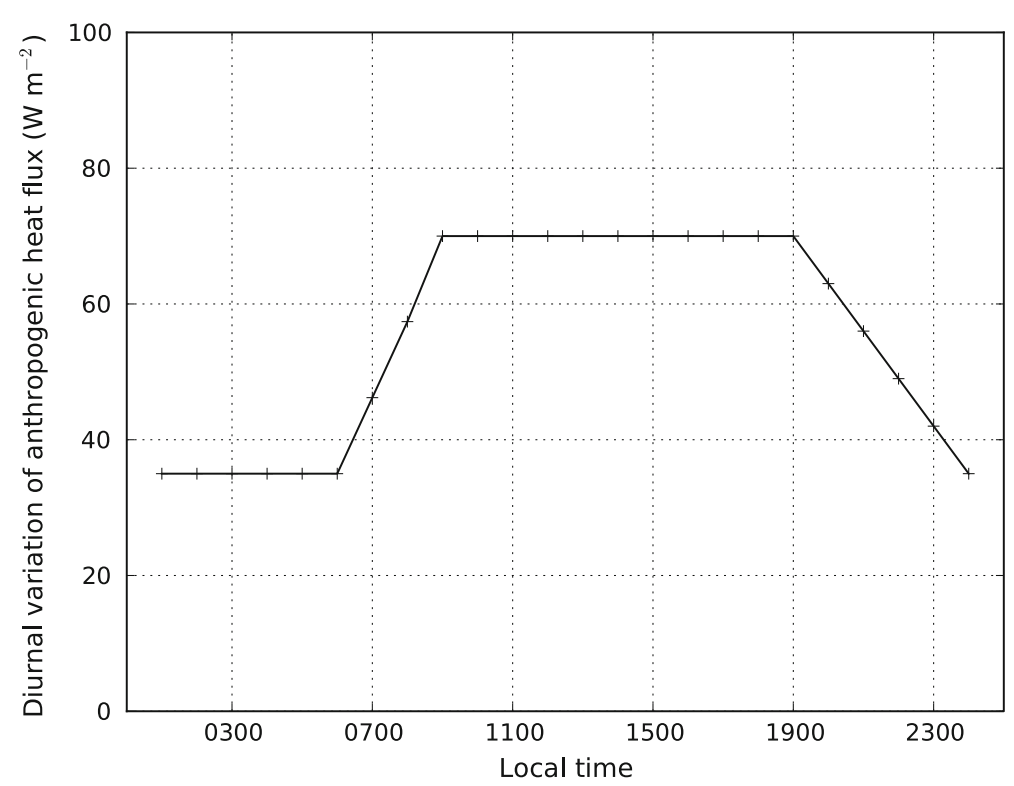

Fig. 1 Diurnal variation of the anthropogenic heat flux for Paris in May
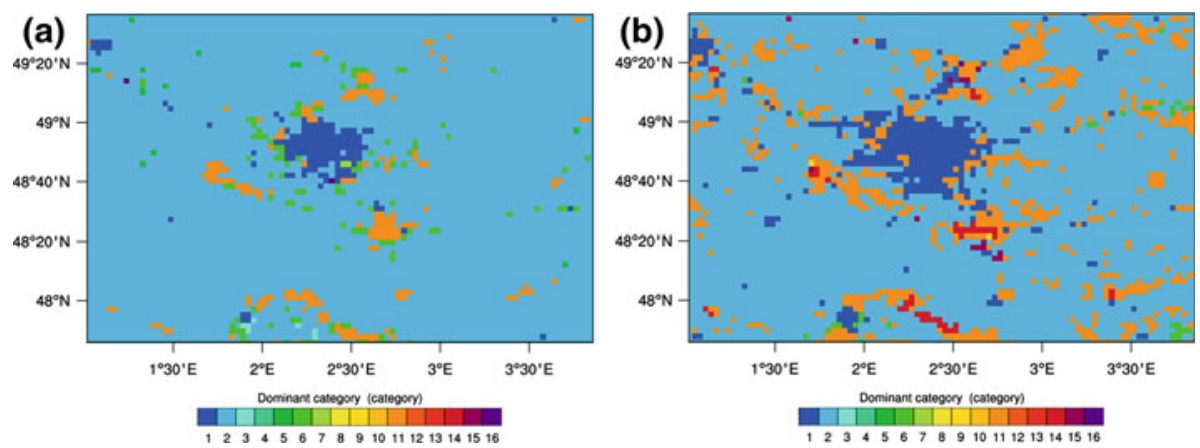

Fig. 2 Land-use categories using a USGS database and $\mathbf{b}$ CORINE database. 1 Urban and built-up land, 2 dryland/cropland and pasture, 3 irrigated cropland and pasture, 4 mixed dryland/irrigated cropland and pasture, 5 cropland/grassland mosaic, 6 cropland/woodland mosaic, 7 grassland, 8 shrubland, 9 mixed shrubland/grassland, 10 savanna, 11 deciduous broadleaf forest, 12 deciduous needleleaf forest, 13 evergreen broadleaf forest, 14 evergreen needleleaf forest, 15 mixed forest, 16 water bodies

\section{Measurements}

We compared the results obtained using the four PBL schemes to meteorological measurements provided by various observatories. Figure 3 presents the locations of the measurement stations. A French national atmospheric observatory, Site Instrumental de Recherche par Télédétection Atmosphérique (SIRTA), provides measurements of wind speed and direction, temperature, pressure, relative humidity and precipitation rate at a ground station located in Palaiseau, $20 \mathrm{~km}$ south-west of Paris, in a semi-urban environment (Haeffelin et al. 2005). 


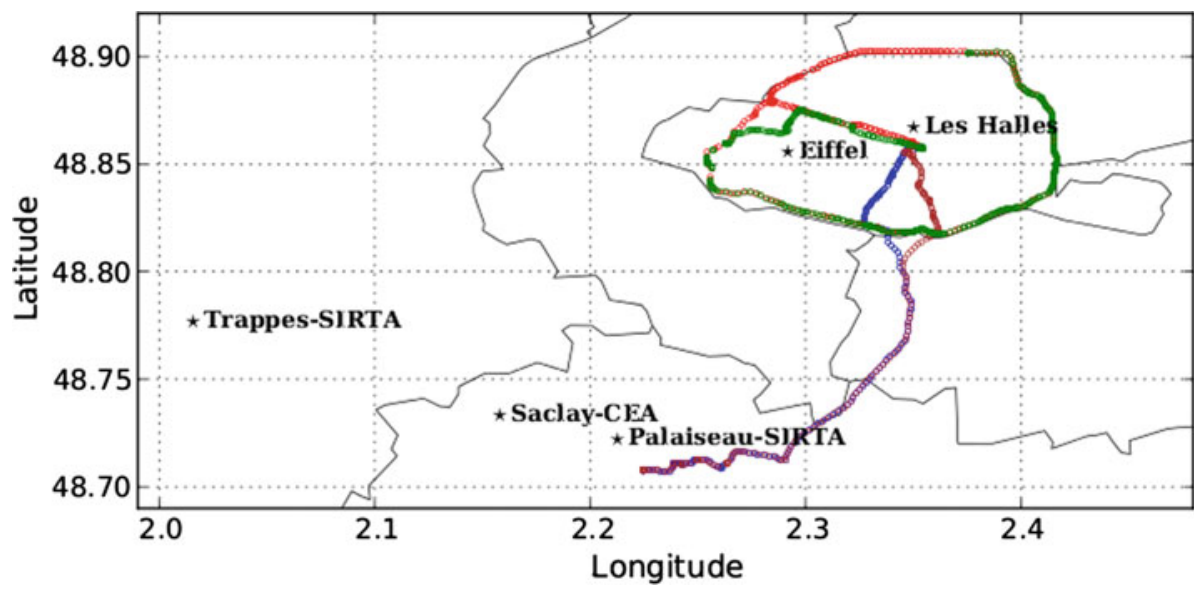

Fig. 3 Locations of meteorological observation stations and route taken for the measurements of the GBML. Blue and brown marks show the route for the measurements from the suburbs of Paris to Paris centre for 24 May and 25 May, respectively. Red marks represent the measurements on the beltway of Paris before rush-hour and green marks represent the measurements on the beltway during rush-hour for 25 May 2005. The black lines show the geographical border of the administrative department

This local-scale station is adequate to compare simulation results of a model horizontal resolution of about $4 \mathrm{~km}$ as used in this work. The station is several hundreds metres away from heat sources such as buildings and from natural fences to avoid extraneous microclimatic influences. Except when a strong synoptic flow exists during the observations, local-scale effects dominate. However the weather conditions (clear sky and weak wind) were favourable to our comparison in the lowest layers of the atmosphere at the SIRTA station during the observation period in May 2005 (Météo-France 2005). SIRTA also provides radiosonde profiles of pressure, temperature, potential/virtual potential temperature, relative/specific humidity, wind speed/direction, and values of PBL height performed at 0000 and 1200 UTC at Trappes as part of the French national meteorological service organization (Météo-France) network. The station at Trappes is $15 \mathrm{~km}$ west of the SIRTA site in Palaiseau and is in an urban environment. Details on the measurements are available at http://sirta.ipsl.polytechnique.fr. The PBL heights at Trappes are estimated using radiosonde profiles of the potential temperature and the estimation method is presented in Sect. 4. The Commissariat à l'Energie Atomique (CEA) operates an observation mast of $100 \mathrm{~m}$ tall in Saclay. Hourly measurements are carried out for wind speed/direction, relative humidity, pressure, precipitation rate, solar radiation and temperature at various heights. The mast is located in a semi-urban environment. The Météo-France operates an observation deck on the Eiffel Tower in Paris, with the hourly measurements carried out at a height of $319 \mathrm{~m}$. The comparison is performed for the period from 6 May to 27 May 2005.

Lidar data are also used to estimate the PBL height. A ground-based mobile lidar (GBML) was used during the air quality observation campaign, LISAIR, over Greater Paris from 24 to 27 May 2005 (Raut and Chazette 2009). Observations of the aerosol extinction coefficients profiles by the GBML were made to retrieve the multiple boundary layers in the troposphere and in turn the vertical distribution of particulate matter (PM) with aerodynamic diameter $<10 \mu \mathrm{m}\left(\mathrm{PM}_{10}\right)$. The lidar used during the LISAIR campaign is a home-made instrument (Chazette et al. 2007); its overlap factor becomes unity at about $150 \mathrm{~m}$ above the ground level. It enables us to retrieve the height of the different aerosol layers, even close to the surface as 
detected in the evening or early morning. The accurate heights of the limits between the multiple layers are obtained from an algorithm enabling the detection of vertical heterogeneities in the aerosol extinction coefficients derived from lidar profiles.

Two kinds of observations were performed with the GBML: the $\mathrm{PM}_{10}$ gradients between the suburbs of Paris and Paris centre were observed, and observations along the main roads (from Les Halles to the Arc de Triomphe through the Avenue des Champs-Élysées) and the beltway of Paris were carried out. Routes followed by the automobile embarking the lidar are presented in Fig. 3. The GBML measurements are detailed in Raut and Chazette (2009).

\section{Estimations of PBL Heights Used in this Study}

The PBL height is not obtained directly but only estimated from measured meteorological fields (e.g., temperature, wind speed and humidity) and from the vertical distribution of trace gas concentrations.

\subsection{Estimations from Measurements}

Radiosonde temperature and wind profiles have been used to estimate the PBL height. Following Coindreau et al. (2007), the PBL height is estimated from radiosonde profiles using a bulk Richardson number $R i_{\mathrm{b}}$ calculated as,

$$
R i_{\mathrm{b}}(z)=\frac{g\left(z-z_{0}\right)}{\theta_{\mathrm{v}}(z)}\left[\frac{\theta_{\mathrm{v}}(z)-\theta_{\mathrm{v}}\left(z_{0}\right)}{u(z)^{2}+v(z)^{2}}\right],
$$

where $\theta_{\mathrm{v}}$ is the virtual potential temperature, $g$ is the acceleration due to gravity, $z$ is the height, $z_{0}$ is the reference height (considered here as the first vertical point available on the sounding profile), and $u$ and $v$ are the zonal and meridional wind components, respectively. The PBL height is estimated at the first height at which the calculated $R i_{\mathrm{b}}$ first exceeds a critical Richardson number. In this study, the critical Richardson number is set to 0.21 following Coindreau et al. (2007).

Various detection criteria have been proposed to find the PBL height from lidar vertical profiles. The PBL height can be detected as the altitude at which the vertical gradient of the extinction coefficient is minimum (Flamant et al. 1997) or where the second derivative is zero (Menut et al. 1999). Other studies rely on mathematical fitting functions (Steyn et al. 1999) or the application of a wavelet covariance transform (Brooks 2003). Here, we analyze the lidar profiles using the curvature radius $\rho$ defined by

$$
\rho(z)=\frac{\mathrm{d}^{2} \alpha}{\mathrm{d} z^{2}}\left[1+\left(\frac{\mathrm{d} \alpha}{\mathrm{d} z}\right)^{2}\right]^{-\frac{3}{2}},
$$

where $\alpha$ is the aerosol extinction coefficient.

First, the vertical profile of $\alpha$ is approximated by a second-order polynomial function using the least mean squares method. This polynomial fit is done in a vertically sliding window of thickness that may vary with the vertical layer structure (100 m on average). Then first and second derivatives of $\alpha$ are numerically computed through an analytical derivation. The curvature radius is obtained by inserting the first and second derivatives into Eq. 2 . The curvature radius provides information on the limits of a transition zone between the PBL and the residual layer. The centre of the transition zone is defined as the minimum gradient in the vertical profile of $\alpha$. The bottom and top of the transition zone are defined as the nearest 
peaks of $\rho$ from the centre of the transition zone. The PBL height is defined as the top of this transition zone (Raut and Chazette 2009). This approach allows us to follow the temporal evolution of the discontinuity in the transition zone independently of the remaining part of the profile. The discontinuity is detected on the first profile of the temporal series, as explained above. The temporal evolution of the discontinuity is then retrieved from the treatment of each individual profile in a 300-m thick window around the altitude detected on the previous profile, insuring the temporal consistency.

\subsection{Estimations from Modelling}

The PBL height is estimated differently in each of the four PBL schemes. The YSU and the ACM2 schemes define PBL height as the height at which the bulk Richardson number is greater than a critical Richardson number. For unstable conditions, the critical Richardson number is zero for the YSU scheme and 0.25 for the ACM2 scheme, while it is 0.25 for both the YSU and the ACM2 schemes for stable conditions. The difference between the YSU and ACM2 schemes is that the Richardson number criterion is applied from the lowest model level for unstable conditions in the YSU scheme, while it is applied across the entrainment layer only in the ACM2 scheme.

In the YSU scheme, the bulk Richardson number is calculated as

$$
R i_{\mathrm{b}}(z)=\frac{g z}{u(z)^{2}+v(z)^{2}}\left[\frac{\theta_{\mathrm{v}}(z)-\theta_{\mathrm{s}}}{\theta_{\mathrm{v}}\left(z_{0}\right)}\right],
$$

where $\theta_{\mathrm{v}}\left(z_{0}\right)$ is the virtual potential temperature at the lowest model level $\left(z_{0}\right), \theta_{\mathrm{v}}(z)$ is the virtual potential temperature at a level $z, \theta_{\mathrm{S}}$ is an appropriate temperature near the surface. The appropriate temperature near the surface is defined as

$$
\theta_{\mathrm{s}}=\theta_{\mathrm{v}}\left(z_{0}\right)+\theta_{T},
$$

where $\theta_{T}$ is the virtual temperature excess near the surface, which is a function of the virtual heat flux from the surface and a wind velocity scale.

In the ACM2 scheme, the top of the convectively unstable layer $\left(z_{\operatorname{mix}}\right)$ is found as the height at which $\theta_{\mathrm{v}}\left(z_{\text {mix }}\right)=\theta_{\mathrm{s}}$. Then the bulk Richardson number is calculated by

$$
R i_{\mathrm{b}}(z)=\frac{g\left(z-z_{\text {mix }}\right)}{\left(u(z)-u\left(z_{\text {mix }}\right)\right)^{2}+\left(v(z)-v\left(z_{\text {mix }}\right)\right)^{2}}\left[\frac{\theta_{\mathrm{v}}(z)-\theta_{\mathrm{s}}}{\overline{\theta_{\mathrm{v}}}}\right],
$$

where $\overline{\theta_{\mathrm{V}}}$ is the average virtual potential temperature between $z_{0}$ and $z$.

The PBL height for the MYJ scheme is defined as the height at which the TKE falls below a minimum value $\left(0.1 \mathrm{~m}^{2} \mathrm{~s}^{-2}\right)$, while it is defined in the MYNN scheme as the height at which the virtual potential temperature is $>0.5 \mathrm{~K}$ than that at the surface.

\section{Comparisons to Measurements: Sensitivity to the PBL Schemes}

The fine-grid simulation results for Greater Paris are used for comparisons to measurements. The statistical indicators used in this study are the root-mean-square error ( $R M S E)$, the mean bias $(M B)$, the mean fractional bias and error $(M F B$ and $M F E)$, the normalized mean bias and error $(N M B$ and $N M E)$ and the correlation coefficient. They are defined in Table 2. 
Table 2 Definitions of the statistical indicators

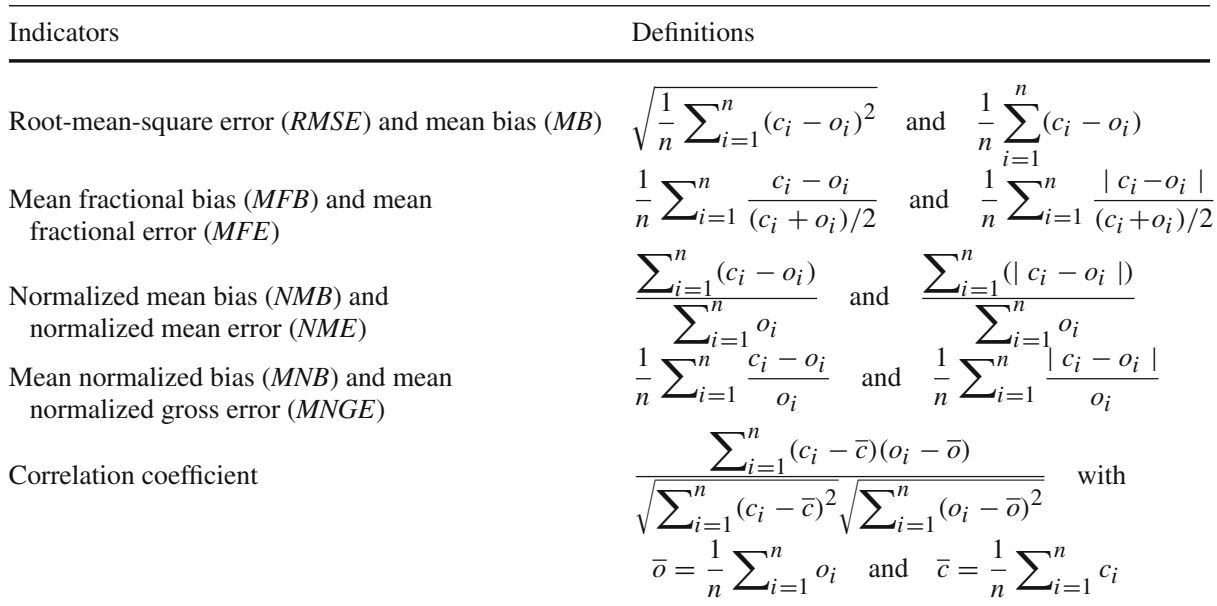

$c_{i}$ modelled values, $o_{i}$ observed values, $n$ number of data

\subsection{Impact on Temperature}

Figure 4 shows the mean diurnal variations of the 2-m temperature at Palaiseau, 100-m temperature at Saclay and 319-m temperature at the Eiffel Tower. The transition from night to day, that is the time at which the temperature starts to increase, is well simulated by all the PBL schemes at Palaiseau. However, at Saclay and at the Eiffel Tower, the transition time is delayed in the simulations compared to the observations by 1 and $2-3 \mathrm{~h}$ respectively. The temperature is underestimated at Palaiseau, Saclay and the Eiffel Tower whatever the PBL scheme used in the simulation. Therefore, the discrepancies may not be due to the PBL scheme but most likely from the radiation model, as the underestimation is stronger during the day.

The differences between the PBL schemes are small, although the statistics obtained with the MYNN scheme are slightly better than others. The underestimations of the 2-m temperature are smaller than those of the temperature at higher altitudes: the $M F B$ varies from -0.06 (the YSU scheme) to -0.15 (the MYJ scheme) and the $N M B$ varies from -0.05 (the YSU and the MYNN schemes) to -0.13 (the MYJ scheme). The differences of the 2-m temperature are due to the differences in the temperature of the skin that forms the interface between soil and atmosphere (not shown). The simulated mean skin temperatures by the YSU scheme (highest) and the ACM2 scheme (lowest) differ by $4^{\circ} \mathrm{C}$ at 1400 UTC at Palaiseau. The differences in the skin temperature result from using a different surface-layer scheme with each PBL scheme (see Sect. 2.3).

The underestimations of the temperature are more significant at the Eiffel Tower than at Palaiseau and Saclay (MFB: -0.24 for the MYNN scheme to -0.41 for the MYJ scheme, $N M B$ : -0.21 for the MYNN scheme to -0.29 for the MYJ scheme). The diurnal cycle and the temperatures are underestimated, particularly during daytime for the temperatures, and the underestimations tend to increase with altitude. The bias of the simulated temperatures consists of two components: a general cold bias and an underestimation of the amplitude of the diurnal cycle. The general cold bias increases with height, and may be due to uncertainties in the radiation model values (in particular, incoming solar radiation during daytime) that increase with height. 
Fig. 4 Mean diurnal variations of observed and modelled temperatures between 6 May and 27 May 2005: a 2-m temperature at Palaiseau, b 100-m temperature at Saclay, and c 319-m temperature at the Eiffel Tower. Black lines correspond to the observed values. The modelled values using each PBL scheme are represented by triangles (the ACM2 scheme), plus (the MYJ scheme), cross (the MYNN scheme) and dots (the YSU scheme). The modelled values using a PBL scheme, the UCM and the CORINE land-use data are represented by dashed lines (the MYNN scheme) and dotted lines (the YSU scheme)
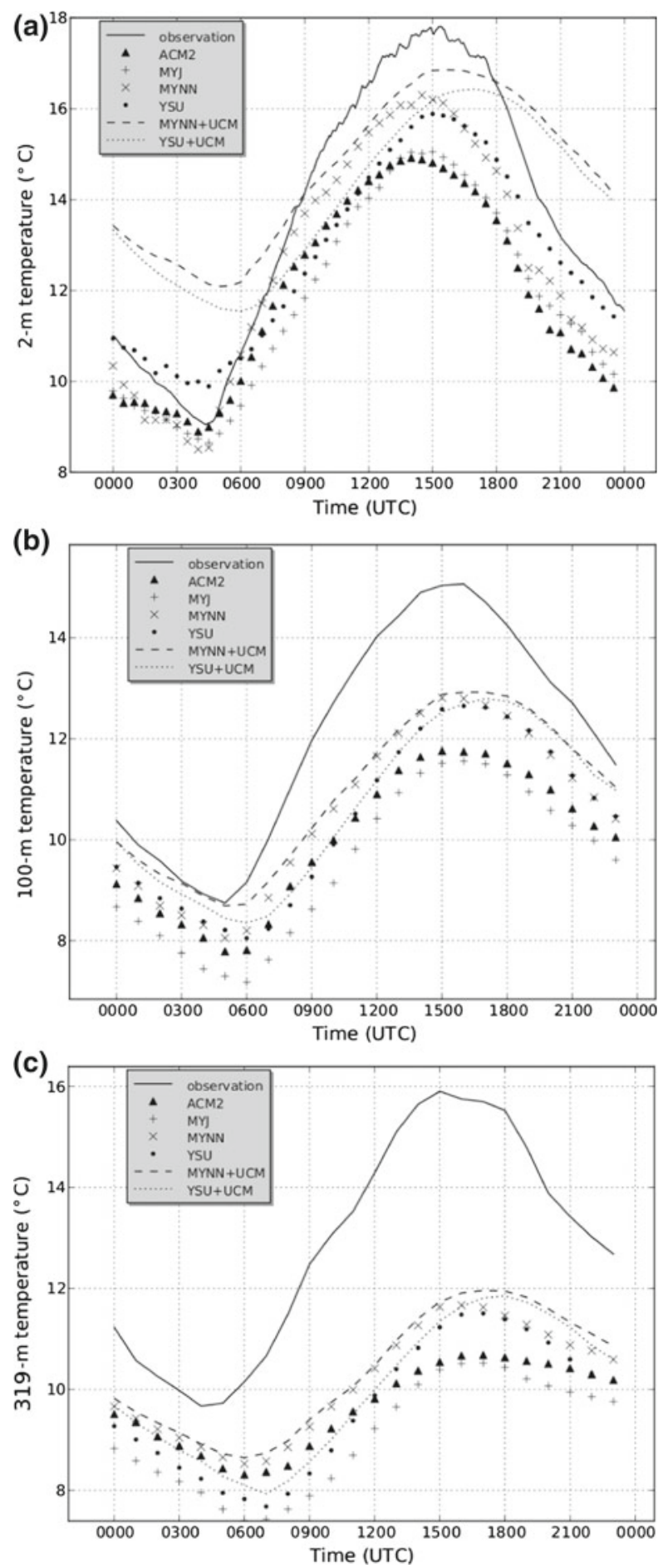
(a)

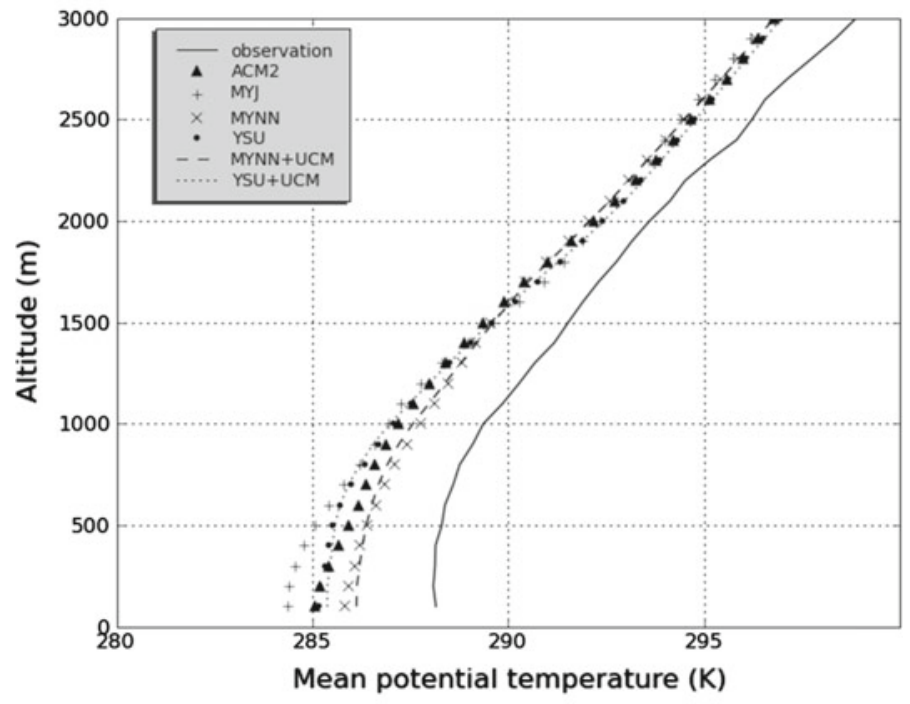

(b)

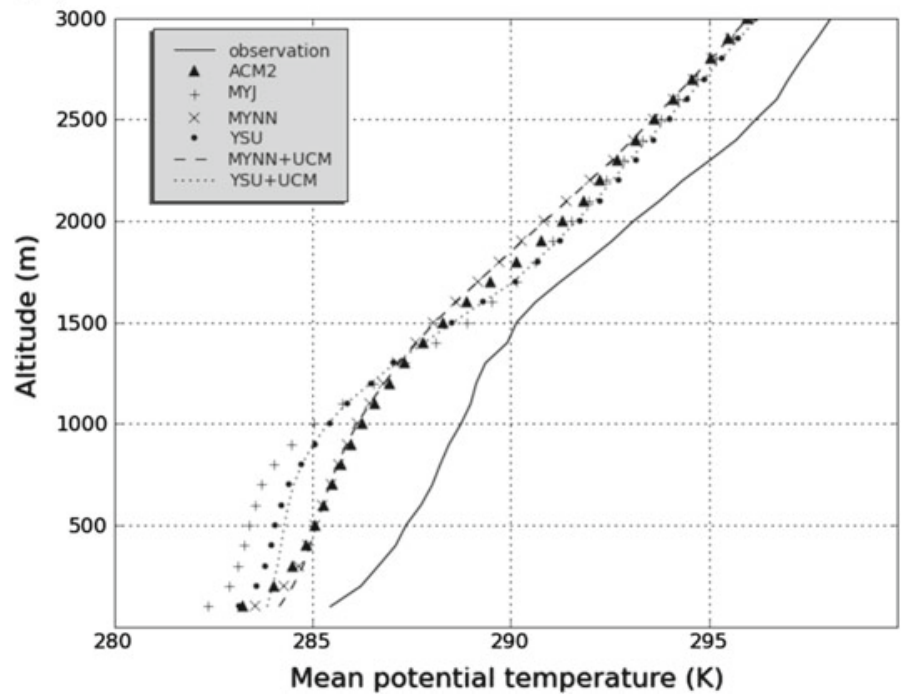

Fig. 5 Mean vertical profiles of observed and modelled potential temperatures at Trappes: a 1200 UTC and b 0000 UTC

Figure 5 compares the observed and simulated mean vertical profiles of potential temperature at Trappes at 0000 and 1200 UTC. All the PBL schemes underestimate the potential temperature for both the daytime and the nighttime observations. The MYNN scheme performs better than others below 1,200 m height at 1200 UTC. The differences between the PBL schemes are large near the surface and decrease with height. This may be due to differences in the surface-layer schemes. The ACM2 and the MYNN schemes perform better than the other two schemes below 1,200 m height at 0000 UTC. The YSU and the MYJ schemes 
show lower potential temperature values (weak stable profiles) between 200 and $700 \mathrm{~m}$. This is consistent with the results at the Eiffel Tower where lower temperatures are simulated with the YSU and the MYJ schemes during nighttime. The weaker stable (more neutral) profiles suggest higher heat diffusivity near the surface in the YSU and MYJ schemes than in the two other schemes.

\subsection{Impact on Wind Speed}

Figure 6 shows the mean diurnal variations of the 10-m wind speed at Palaiseau, 110-m wind speeds at Saclay and 319-m wind speed at the Eiffel Tower. For the 10-m wind speed, the morning transition at which the wind speed increases, is observed at about $0500 \mathrm{UTC}$, and it is well simulated by the PBL schemes, except for the ACM2 scheme that simulates an earlier transition. The statistics obtained with the MYNN scheme are overall improved on the others. The $10-\mathrm{m}$ wind speed is overestimated with all the schemes. The overestimation of the MYJ scheme (MFB: 0.73) is slightly higher than others (MFB: 0.66, 0.62 and 0.61 for the YSU, the ACM2 and the MYNN schemes respectively). This overestimation of the 10-m wind speed may be partly attributed, especially during nighttime, to an underestimation of the friction velocity, which depends on the surface-layer schemes.

Morning and evening transitions, where wind speed increases and decreases respectively, are clearly defined for the 110-m and the 319-m wind speeds. However there are time differences between observations and simulations, which are similar to those for the temperature diurnal cycle. Therefore the differences could be due to the uncertainties in the radiation models. The errors and bias of the 110-m wind speed at Saclay are lower than the 10-m wind speed at Palaiseau except for the RMSE that increases with the ACM2 and the MYNN schemes. The 319-m wind speed is overestimated with all the schemes. The bias between the simulated values and the observed values are lower than those of the 10-m wind speed (about a third); however magnitudes of the errors are similar. Statistics obtained with the YSU scheme are the best among the schemes.

Figure 7 presents the observed and simulated mean vertical profiles of wind speed at Trappes at 0000 and 1200 UTC. The four schemes overestimate the wind speed from the ground to around $1,000 \mathrm{~m}$ in the daytime profile and they underestimate it above 1,000 $\mathrm{m}$. The overestimations near the surface may be partly due to an underestimation in the friction velocities in the surface-layer schemes, especially during nighttime. During daytime, except for the correlation coefficient, the YSU scheme shows the best statistics. The larger discrepancies between the different schemes are observed at night in the first 1,000 $\mathrm{m}$. Close to the surface, the wind speed is underestimated by all the schemes at night. The wind speed decreases near the surface with all the schemes and a low-level jet develops at around $500 \mathrm{~m}$ of height. The low-level jet with the ACM2 and the MYNN schemes is stronger $\left(11 \mathrm{~m} \mathrm{~s}^{-1}\right.$ at peak) than that with the YSU and the MYJ schemes $\left(9 \mathrm{~m} \mathrm{~s}^{-1}\right.$ at peak). The value of the peak of the observed low-level jet is about $10 \mathrm{~m} \mathrm{~s}^{-1}$, i.e., between the values of the simulated peaks, and the observed peak is vertically lower $(200 \mathrm{~m})$ than the simulated peaks $(300-500$ $\mathrm{m})$. During nighttime the YSU and the MYJ schemes show the best statistics.

\subsection{Impact on Humidity}

Figure 8 displays the mean diurnal variations of surface relative humidity $(r)$ and specific humidity $(q)$ at Palaiseau; $r$ is overestimated by all the schemes (bias: about 0.10 for the YSU scheme to 0.20 for the ACM2 scheme). The statistics obtained with the YSU scheme are slightly better than the others, except for the correlation coefficient, which is greater 
Fig. 6 Mean diurnal variations of observed and modelled wind speeds: a 10-m wind speed at Palaiseau, b 110-m wind speed at Saclay, and c 319-m wind speed at the Eiffel Tower. For the detailed caption of the figure, see Fig. 4
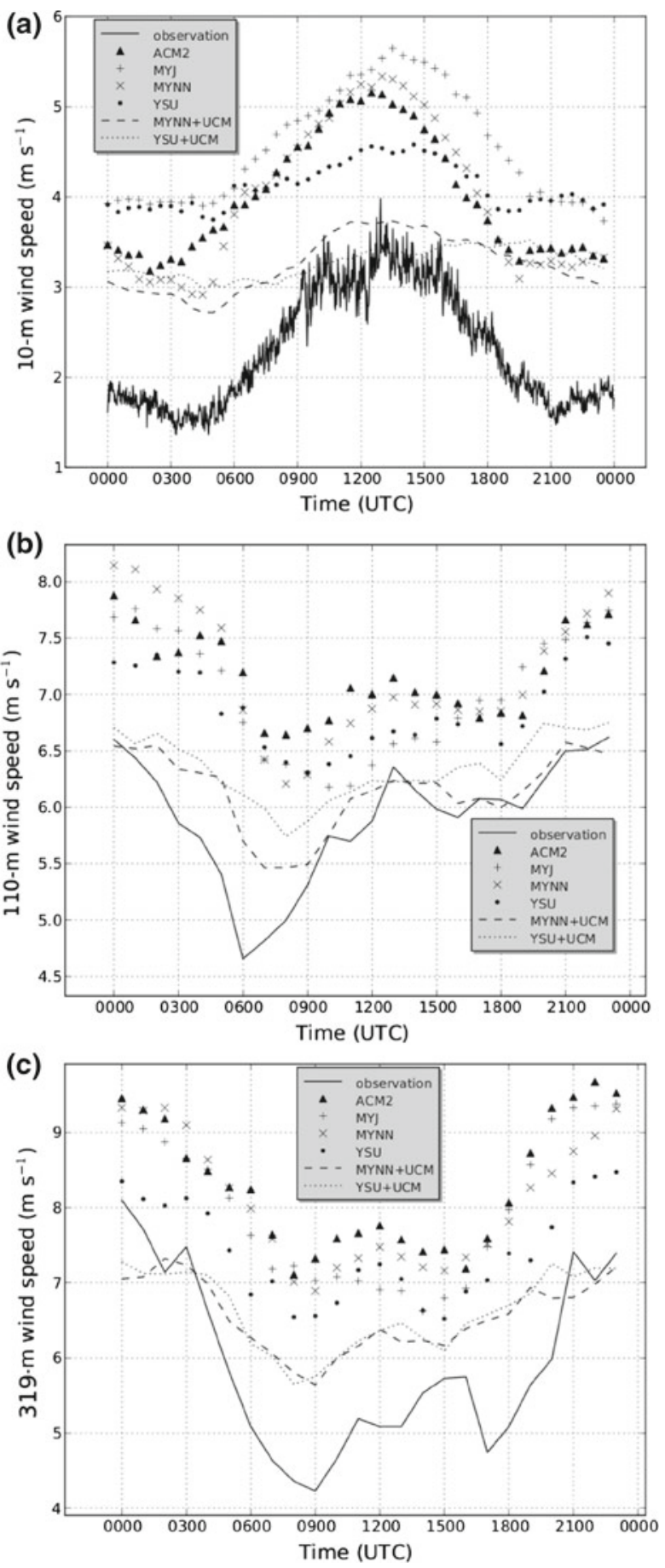

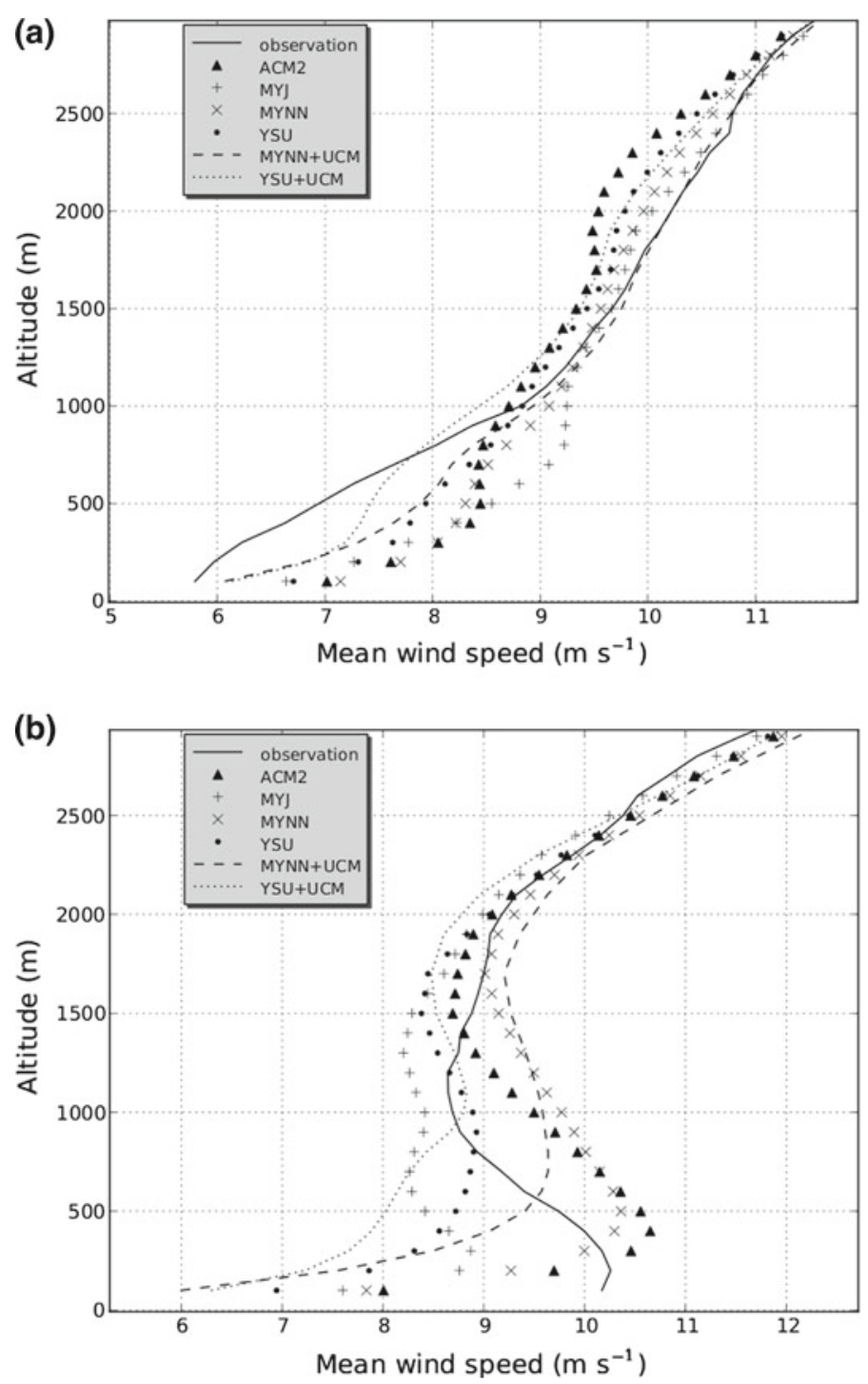

Fig. 7 Mean vertical profile of observed and modelled wind speeds at Trappes: a 1200 UTC and b 0000 UTC. For the detailed caption of the figure, see Fig. 4

with the MYNN scheme (0.74). Overestimations of $r$ are mostly due to overestimations of $q$ during daytime, and to underestimations of the temperature during nighttime.

The observed and simulated mean vertical profiles of $q$ are compared at Trappes (not shown). During daytime, the four PBL schemes overestimate $q$ below about 1,500 m except for the MYJ scheme, which underestimates $q$ between 700 and 1,000 m. The $q$ simulated with the MYJ scheme is higher between the surface and $400 \mathrm{~m}$, because of weaker vertical mixing in the MYJ scheme. The MYNN scheme, which has improved vertical mixing, simulates similar results to the two non-local schemes (Nakanishi and Niino 2009). The MFE in the YSU scheme is improved on the others while the RMSEand the NME in the MYNN scheme 


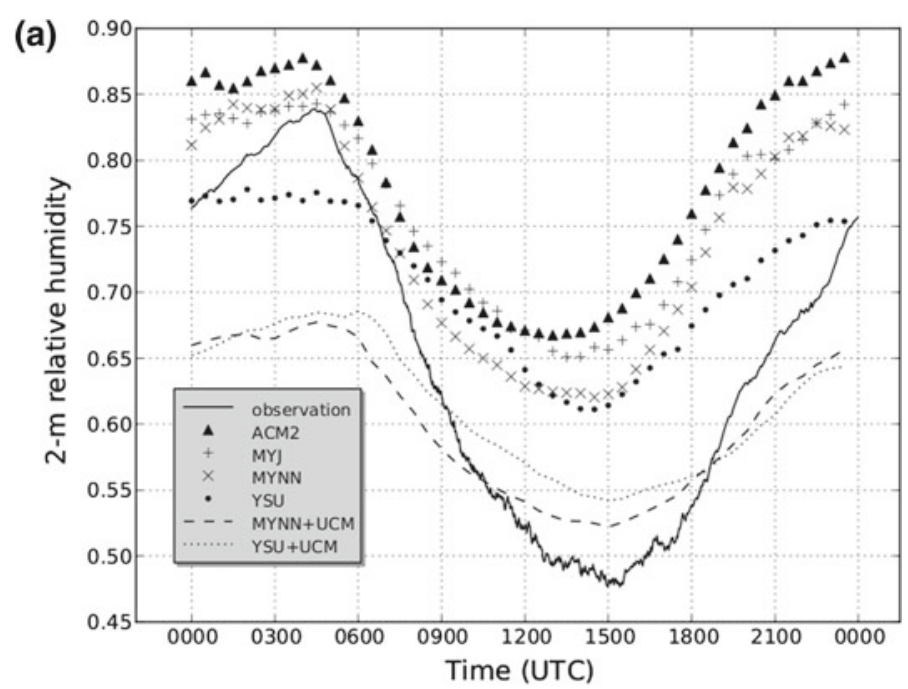

(b)

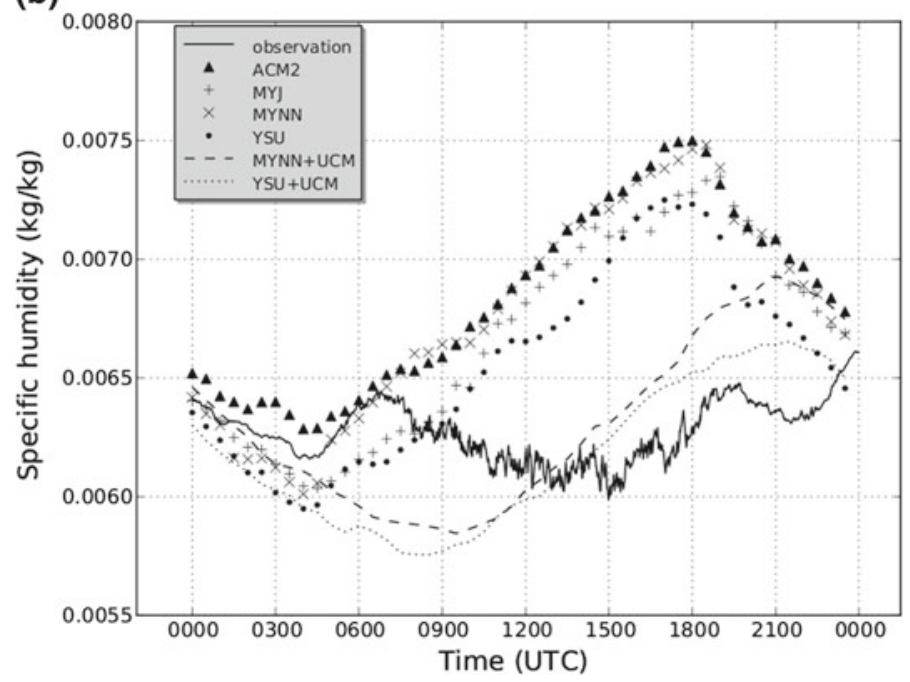

Fig. 8 Mean diurnal variation of observed and modelled a surface relative humidity and $\mathbf{b}$ specific humidity at Palaiseau. For the detailed caption of the figure, see Fig. 4

are optimal. During nighttime, the MYNN scheme has lower errors while the YSU and the MYJ schemes have lower biases.

\subsection{Impact on PBL Height}

The PBL heights modelled by the PBL schemes and retrieved by the radiosonde at Trappes are compared in Table 3. During daytime, the PBL schemes mainly underestimate the PBL heights except for the MYJ scheme. The lowest monthly mean error is obtained with the YSU scheme. The maximum difference in the modelled mean PBL heights among the PBL schemes is $20 \%$ (135 m between the MYNN and the MYJ schemes). During nighttime, the 
Table 3 Comparison of observed PBL heights (m) from radiosonde to modelled PBL heights

\begin{tabular}{|c|c|c|c|c|c|}
\hline & Radiosonde & ACM2 & MYJ & MYNN & YSU \\
\hline \multicolumn{6}{|l|}{ Daytime } \\
\hline Using the parametrization & 990 & 1,065 & 975 & 1,111 & 1,105 \\
\hline Using the common algorithm & & 972 & 1,070 & 891 & 963 \\
\hline \multicolumn{6}{|l|}{ Nighttime } \\
\hline Using the parametrization & 407 & 224 & 593 & 150 & 652 \\
\hline Using the common algorithm & & 401 & 554 & 450 & 730 \\
\hline
\end{tabular}

The modelled heights calculated using the algorithms from the parametrizations are compared to those using the common algorithm

YSU and the MYJ schemes overestimate the PBL heights while the ACM2 and the MYNN schemes underestimate them. Modelled mean PBL heights are significantly different among the schemes (from $150 \mathrm{~m}$ for the MYNN scheme to $652 \mathrm{~m}$ for the YSU scheme, $335 \%$ ). The mean value of the modelled mean heights for all the schemes $(405 \mathrm{~m})$ is the best estimation for the observed mean height (407 m).

As discussed in Sect. 4, different methods are used in the PBL schemes to determine the PBL height. Besides, the method to detect the PBL height from the radiosonde observations $(\theta$-profile method hereafter) is different from that used with the simulated data. To remove discrepancies from using different methods in the PBL height diagnosis, the simulated PBL heights are recalculated using the $\theta$-profile method used for the radiosonde data (see Sect. 3). The mean simulated PBL heights during both daytime and nighttime with the $\theta$-profile method are presented in Table 3. As expected, the discrepancies in the PBL heights from the different PBL schemes are significantly reduced using the common $\theta$-profile method. Furthermore, the bias between the observed height and the simulated height is reduced except for the height during nighttime obtained with the YSU scheme.

We compare the PBL heights estimated by the GBML measurements to the modelled PBL heights; Fig. 9a, b present the PBL heights estimated by the lidar from the suburbs of Paris (Palaiseau) to Paris centre (Les Halles) on 24 May and 25 May, respectively.

In Fig. 9a, the heights do not significantly vary during the measurements on 24 May. The height at Palaiseau is $444 \mathrm{~m}$ while the height at Les Halles is $486 \mathrm{~m}$. This weak increase of the PBL height could be explained by uncertainties in the algorithm used to calculate the PBL height from the aerosol extinction coefficients. According to the vertical distribution of $\mathrm{PM}_{10}$ on 24 May at about 0400 UTC presented in the Fig. 4 of Raut and Chazette (2009), two layers are seen above the whose top is estimated to be at about $500 \mathrm{~m}$. One layer extends from 600 to $700 \mathrm{~m}$ and the other one from 750 to $1,500 \mathrm{~m}$. The highest layer should correspond to the residual layer. However it is not clear whether the layer between 600 and $700 \mathrm{~m}$ should be considered as part of the residual layer or as part of the PBL. If it is considered as part of the PBL, the PBL height would then be about $700 \mathrm{~m}$, which corresponds to the height modelled using the YSU scheme. All the PBL schemes underestimate the PBL heights except for the YSU scheme at the Paris centre where the modelled heights increase to about $750 \mathrm{~m}$. This increase of the modelled PBL height by the YSU scheme at the Paris centre can be explained by the vertical profiles of potential temperature. The potential temperature at the surface is similar to that around $750 \mathrm{~m}$ of height (difference $<1.0 \mathrm{~K}$ ), leading to a more neutral profile and resulting in an increase in PBL height.

In Fig. 9b, the PBL height at Palaiseau at 0300 UTC on 25 May is about $320 \mathrm{~m}$ while the height at Les Halles at 0400 UTC is about $480 \mathrm{~m}$. The PBL height does not significantly 

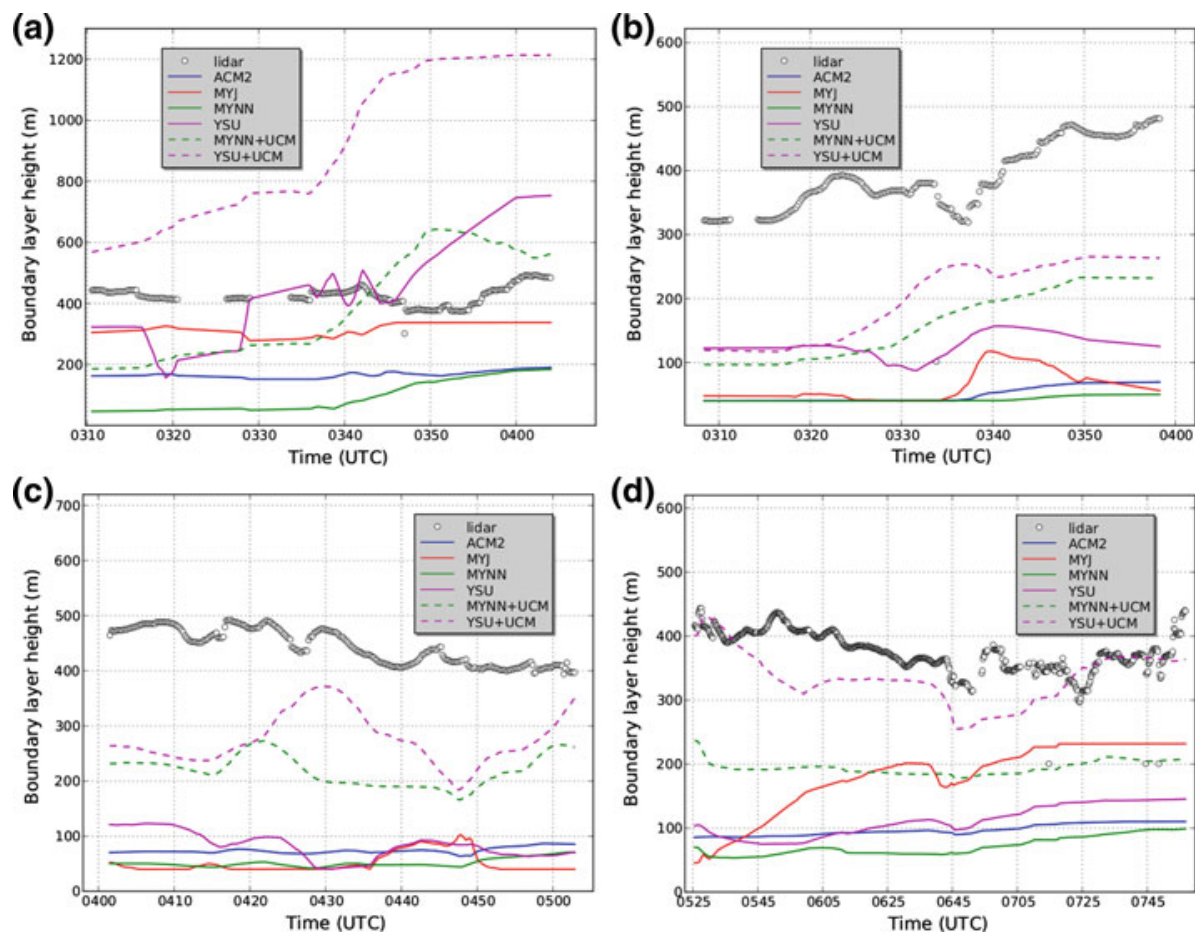

Fig. 9 Boundary-layer heights estimated by the GBML and modelled heights: from Palaiseau to Paris on a 24 May and b 25 May; at the main road and the beltway of Paris on 25 May c before rush-hour and d during rush-hour. The black circles correspond to the values observed by the GBML. The modelled values using each PBL scheme are represented by a blue line (the ACM2 scheme), red line (the MYJ scheme), green line (the MYNN scheme) and magenta line (the YSU scheme). The modelled values using a PBL scheme, the UCM and the CORINE land-use data are represented by a green dashed line (the MYNN scheme) and a magenta dashed line (the YSU scheme)

increase from 0300 UTC to 0400 UTC because sunrise at Paris at the end of May is about 0400 UTC. Therefore, the increase of the PBL height at Les Halles compared to that at Palaiseau is explained by the stronger urban heat release at Les Halles. All the PBL schemes significantly underestimate the PBL heights. The mean modelled PBL heights are lower than $100 \mathrm{~m}$ except for the YSU scheme $(130 \mathrm{~m})$ while the mean height observed by the lidar is about $390 \mathrm{~m}$. This discrepancy is partly due to uncertainties in modelling the nighttime heat flux due to human activities in the urban region and to uncertainties in modelling the stable conditions, as shown by the vertical profiles of potential temperature. The modelled temperature at $200 \mathrm{~m}$ is probably overestimated, and is higher than that at the surface, resulting in very stable conditions. This increase of the PBL heights observed by the lidar when moving from rural to urban areas on 25 May (but not on 24 May) may be explained by the difference in temperature between Palaiseau and Paris City Hall. The difference measured by these two fixed stations is about $5 \mathrm{~K}$ on 25 May and $2 \mathrm{~K}$ on 24 May. Therefore, the warming of the urban surface is more important on 25 May than on 24 May, resulting in a greater PBL height at the Paris centre on 25 May (see Fig. 9b).

Figure 9c, d present the PBL heights along the main road and the beltway of Paris before rush-hour (from 0400 to 0500 UTC) and during rush-hour (from 0530 to 0800 UTC), respectively. The mean PBL heights estimated by the lidar are $445 \mathrm{~m}$ before rush-hour and $378 \mathrm{~m}$ 
during rush-hour while the mean modelled heights are $<80 \mathrm{~m}$ before rush-hour and $<180 \mathrm{~m}$ during rush-hour. All the PBL schemes underestimate the PBL heights; the YSU and the MYJ schemes perform slightly better before and during rush-hour than others.

The PBL heights for the GBML measurements vary greatly with the PBL scheme: the maximum difference between the mean PBL heights of the PBL schemes is important for the case of Palaiseau to Paris on 24 May (78 \%) compared to the others (66\% for Palaiseau to Paris on 25 May, $40 \%$ for the beltway of Paris before rush-hour and $60 \%$ for the beltway of Paris during rush-hour).

To summarize, for air temperature, the MYNN scheme presents the best performance although the diurnal cycle and the temperature are underestimated particularly during daytime. For the wind speed, the YSU and the MYNN schemes perform better than the others. The YSU and the MYNN schemes perform better for the relative humidity and the specific humidity, as well. For the PBL height, the YSU scheme performs better than the others but still underestimates significantly the PBL height. As no direct measurement of the PBL height exists, the observed PBL height is diagnosed in various ways, e.g., using the aerosol lidar measurements, as explained in Sect. 3, and using the virtual potential temperature. Because the method used to retrieve the PBL height influences the results, the underestimation of the modelled PBL heights is partly due to the use of different methods of diagnosis.

\section{Effects of the UCM and the CORINE Land-Use Data}

Impacts of the UCM and the CORINE land-use data on the meteorological fields are studied by comparing the reference simulations of the previous section (hereafter Reference) to simulations that use the UCM coupled to the CORINE land-use data (hereafter UCM-CORINE). Simulations are compared for the two PBL schemes that were the best performed in the previous section (the YSU and the MYNN schemes).

\subsection{Impact on Temperature}

When the UCM is used, the sensible heat flux in the urban area increases. The increase is due to the anthropogenic heat flux and to differences in energy balance resulting from different geometric and thermal parameters in the UCM. The increase of the sensible heat flux results in an increase in surface temperature. The surface temperatures for the UCMCORINE simulations are higher than the Reference simulations, especially during nighttime (0.8 K on average for both YSU and MYNN, see Fig. 4). Influences of the UCM and the CORINE land-use data on the 100-m temperature are lower than influences on the 2-m temperature, partly because the 2-m level is within the urban canopy. Outside the canopy (100m temperature), the UCM-CORINE performs better than the Reference, as the temperature is underestimated by the model. Although this underestimation is resolved using UCMCORINE during nighttime at Saclay, it persists at the Eiffel Tower. The transition from night to day for the 2-m temperature is delayed by about $1 \mathrm{~h}$ in the UCM-CORINE simulations. This may be due to a delayed transition of the skin temperature when the UCM is used compared to simulations without the UCM.

The UCM reduces the amplitude of the diurnal cycle of the 2-m temperature at Palaiseau. It is due to the urban heating arising from the anthropogenic heat flux taken into account in the UCM, which has a strong impact on the temperature near the surface during nighttime. The impact of the anthropogenic heat flux on the upward heat flux is significant during nighttime. However it is not significant during daytime, reducing the amplitude of the diurnal cycle. 
Although this reduction is significant for the 2-m temperature, it is low at higher altitudes (see Fig. 4b, c with the 100-m temperature at Saclay and the 319-m temperature at the Eiffel Tower).

The observed temperature diurnal amplitude at Palaiseau is closer to the Reference simulations than to the UCM simulations. This may be due to the use of a single urban land-use category in our UCM simulations. As explained in Sect. 3, the station at Palaiseau is located in a semi-urban environment. However, as we do not distinguish semi-urban areas from urban areas in our simulations, the urban effect may be overestimated at Palaiseau. In addition, the footprint of the station for 2-m temperature measurements may be $<100 \mathrm{~m}$, which is much smaller than the grid size (Oke 2006). Footprints usually increase with the height of measurements. Therefore, footprints for the 100-m temperature measurements at Saclay and the 319-m temperature measurements at the Eiffel Tower may be larger than those for the 2-m temperature. The 100- and 319-m temperatures are more representative of the grid sizes used in the simulations.

Influences of the UCM and the CORINE land-use data on the mean vertical profiles of potential temperature at Trappes are low and confined to the lowest altitudes. The maximum differences between the UCM-CORINE and the Reference at $100 \mathrm{~m}$ altitude are only $0.3 \mathrm{~K}$ during daytime and $0.5 \mathrm{~K}$ during nighttime (not shown).

\subsection{Impact on Wind Speed}

As shown in Fig. 6, the 10-m wind speed at Palaiseau is closer to measurements during daytime when the UCM and the CORINE land-use data are used. The lower 10-m wind speed is attributed to increasing roughness length in the UCM. The roughness length for urban areas defined in the Noah land surface model is $0.5 \mathrm{~m}$. When the UCM is used, the roughness length over urban areas is recalculated using the formulation of Macdonald et al. (1998). In this study, we obtained a roughness length of $2.8 \mathrm{~m}$ using the parameters described in Table 1 (building height, roof width and road width). However the 10-m wind speed is still overestimated in all simulations during nighttime.

The 110-m wind speed at Saclay is much lower and closer to measurements in the UCMCORINE simulation than in the Reference simulation for both the YSU and the MYNN schemes. The UCM-CORINE simulation produces better results for the 10-m wind speed and the 110-m wind speed, because the modelled wind speed is lower and in much better agreement with the measurements. As shown in Fig. 7, for the vertical profiles at Trappes, influences of the UCM and the CORINE land-use data on the wind speed during both daytime and nighttime are important below 1,000 m height, especially during nighttime. Maximum differences between the UCM-CORINE and the Reference is $1 \mathrm{~m} \mathrm{~s}^{-1}$ for the YSU scheme and $2 \mathrm{~m} \mathrm{~s}^{-1}$ for the MYNN scheme at $100 \mathrm{~m}$ during nighttime.

\subsection{Impact on Humidity}

For the relative humidity $(r)$ at Palaiseau, as shown in Fig. 8, the differences between the UCM-CORINE simulation and the Reference simulation are significant (about $15 \%$ of mean $r$ ) for both the YSU and the MYNN schemes. During nighttime, lower $r$ at the ground in the UCM-CORINE simulation is due to higher surface temperature. However during daytime, lower $r$ is due to lower specific humidity $(q)$, which results from stronger vertical mixing in the boundary layer influenced by the anthropogenic heat release in the UCM-CORINE simulation. 

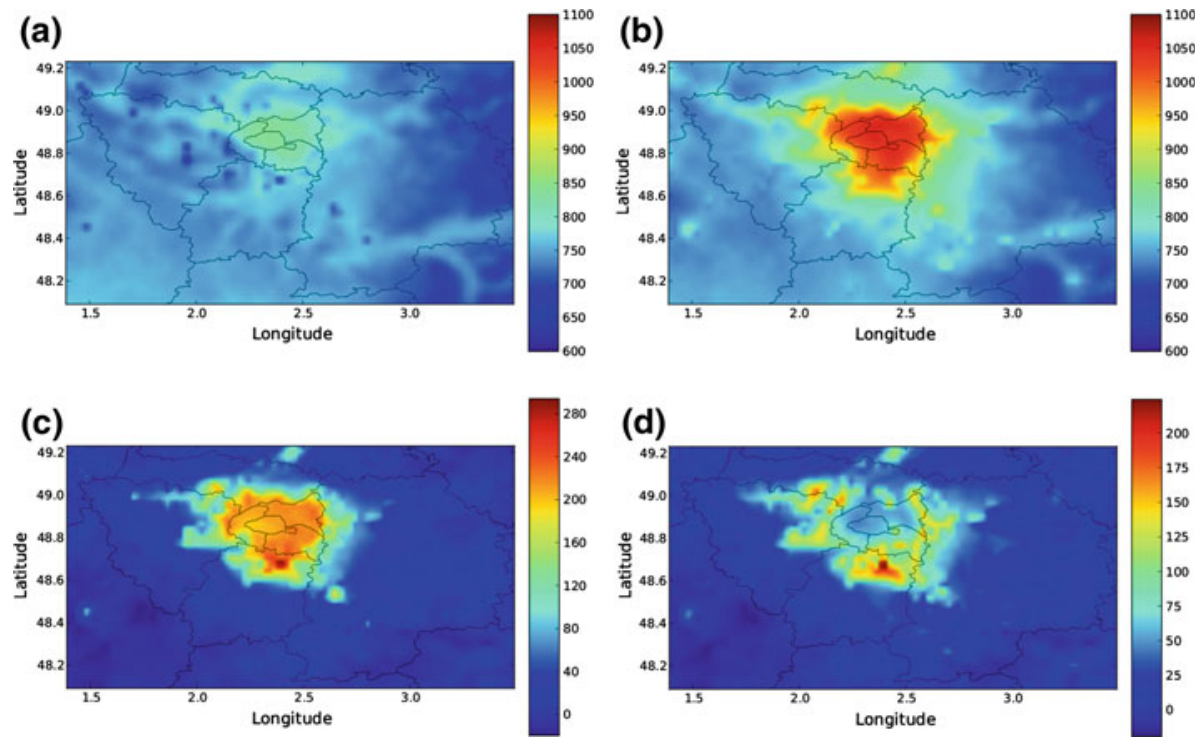

Fig. 10 Modelled mean PBL heights (m) from 6 May to 27 May: a Reference simulation with the YSU scheme, b UCM-CORINE simulation with the YSU scheme, $\mathbf{c}$ differences between the UCM-CORINE and the Reference simulations, and d differences between the UCM-CORINE simulation and the simulation with the UCM and the USGS land-use data. The black lines show the geographical border of the administrative department

The variations of the vertical profiles of $q$ at Trappes are influenced by the stronger vertical mixing in the UCM-CORINE simulation (not shown). Lower $q$ is simulated by the UCMCORINE than by the Reference near the surface while $q$ with the UCM-CORINE at higher altitudes is slightly higher than with the Reference.

\subsection{Impact on PBL Height}

The UCM increases the PBL height over urbanized surface. This increase is more important during nighttime than during daytime. Accordingly, the increase with the UCM-CORINE simulation of the modelled PBL heights at Trappes is $8 \%$ for the YSU scheme and $5 \%$ for the MYNN scheme during daytime while it is $15 \%$ for the YSU scheme and $200 \%$ for the MYNN scheme during nighttime. Figure 10a, b display the mean PBL heights from 6 May to 27 May over Greater Paris by simulations with and without the UCM and the CORINE land-use data. The PBL heights are greater with the UCM-CORINE simulation than with the Reference simulation in Paris and the near suburbs. The maximum difference of the mean PBL height is about 290 m near Orly airport located south of Paris (see Fig. 10c). The effect of using the CORINE land-use data rather than the USGS data is shown in Fig. 10d, which shows differences of the PBL height between the UCM-CORINE simulations and a simulation with the UCM and the standard USGS land use. The influence of the CORINE land-use data on the PBL height is not significant in Paris while it is significant over urbanized areas mostly between 10 and $30 \mathrm{~km}$ from Paris.

Compared to the GBML measurements, modelled PBL heights are also significantly influenced by the UCM and the CORINE land-use data (see Fig. 9). For the measurements from Palaiseau to Paris centre, as well as for the measurements at the main road and the beltway of 
Table 4 Statistical comparisons of modelled values to observed values in this study and in previous studies using urban models
* The combined results of the simulation using the YSU PBL scheme, the UCM and the CORINE land-use data and the simulation using the MYNN PBL scheme, the UCM and the CORINE land-use data

\begin{tabular}{|c|c|c|}
\hline & $R M S E$ & $M B$ \\
\hline \multicolumn{3}{|l|}{ Temperature (K) } \\
\hline Flagg and Taylor (2011) & 2.71 to 4.01 & -4.90 to 0.38 \\
\hline Grossman-Clarke et al. (2010) & 1.0 to 3.0 & -2.0 to 2.0 \\
\hline Lee et al. (2010) & 0.6 to 1.8 & -1.2 to 1.0 \\
\hline Salamanca et al. (2011) & 2.56 & -1.46 \\
\hline Miao et al. (2009) & 1.46 to 3.62 & -0.84 to 0.87 \\
\hline This study* & 2.39 to 3.99 & -2.91 to 0.94 \\
\hline \multicolumn{3}{|l|}{ Mixing ratio $\left(\mathrm{g} \mathrm{kg}^{-1}\right)$} \\
\hline Flagg and Taylor (2011) & 0.70 to 5.44 & -4.90 to 0.38 \\
\hline Grossman-Clarke et al. (2010) & n.a. & n.a. \\
\hline Lee et al. (2010) & n.a. & n.a. \\
\hline Salamanca et al. (2011) & n.a. & n.a. \\
\hline Miao et al. (2009) & 1.8 to 2.78 & -2.26 to -1.17 \\
\hline This study* & 0.71 to 0.84 & -0.02 to 0.20 \\
\hline \multicolumn{3}{|l|}{ Wind speed $\left(\mathrm{m} \mathrm{s}^{-1}\right)$} \\
\hline Flagg and Taylor (2011) & 1.92 to 2.96 & -0.36 to 1.91 \\
\hline Grossman-Clarke et al. (2010) & 1.0 to 3.0 & -2.0 to 2.0 \\
\hline Lee et al. (2010) & 0.6 to 1.4 & -0.2 to 1.0 \\
\hline Salamanca et al. (2011) & n.a. & n.a. \\
\hline Miao et al. (2009) & 0.88 to 1.87 & -0.17 to 1.38 \\
\hline This study* & 1.49 to 2.76 & 0.23 to 0.98 \\
\hline \multicolumn{3}{|l|}{ PBL height (m) } \\
\hline Flagg and Taylor (2011) & n.a. & n.a. \\
\hline Grossman-Clarke et al. (2010) & n.a. & n.a. \\
\hline Lee et al. (2010) & 226 to 382 & 169 to 329 \\
\hline Salamanca et al. (2011) & n.a. & n.a. \\
\hline Miao et al. (2009) & n.a. & n.a. \\
\hline This study* & 54 to 596 & -288 to 539 \\
\hline
\end{tabular}

Paris, the UCM-CORINE simulations produce better results than the Reference simulations, as the modelled PBL heights are higher. However, PBL heights are still underestimated on 25 May (see Fig. 9b). Although the surface atmospheric stability is reduced by higher surface temperatures using the UCM, this influence is not significant because of a strong temperature inversion (increase in temperature with altitude) for the modelled temperatures at low altitudes.

\subsection{Comparison to Previous Studies}

The model performance presented above are also briefly compared to some recent studies using the WRF model (Miao et al. 2009; Grossman-Clarke et al. 2010; Lee et al. 2010; Flagg and Taylor 2011; Salamanca et al. 2011) (see Table 4). Miao et al. (2009) used measurements at 60 surface stations and a wind profiler over Greater Beijing on August 2005. GrossmanClarke et al. (2010) used measurements at 18 surface stations in the Phoenix metropolitan area 
during summer extreme heat events for the years 1973, 1985, 1998, 2005. Lee et al. (2010) used Texas air quality study 2006 field campaign data that included surface measurements, radar wind profilers, boundary-layer height measurements from airborne and ship-based lidars. The simulations were performed over the Houston metropolitan area for a period from 12 to 17 August 2006. Flagg and Taylor (2011) used the Border Air Quality and Meteorology Study (BAQS-Met) 2007 field data that include measurements from an aircraft conducted at various heights across south-western Ontario and adjacent areas around Detroit from 3 to 7 July 2007. They also used radiosonde measurements at White Lake, Michigan and VHF wind profiler measurements at Harrow. Salamanca et al. (2011) used surface measurements over Houston for two days in August 2000.

For the temperature, the mean RMSE obtained in this study $(3.19 \mathrm{~K})$ is higher than that of the previous studies $(2.33 \mathrm{~K})$. However, the mean $M B$ in this study ranges between the maximum and the minimum of the previous studies. For the mixing ratio, the mean RMSE in this study $\left(0.78 \mathrm{~g} \mathrm{~kg}^{-1}\right)$ is lower than that of the previous studies and a lowest bias is also obtained. For the wind speed, the mean RMSE obtained in this study $\left(2.13 \mathrm{~m} \mathrm{~s}^{-1}\right)$ is slightly higher than that of the previous studies $\left(1.96 \mathrm{~m} \mathrm{~s}^{-1}\right)$ while the bias in this study is lower than that of the previous studies. For the PBL height, the mean RMSE in this study $(325 \mathrm{~m})$ is similar to that $(304 \mathrm{~m})$ in Lee et al. (2010) while the bias is higher (414 $\mathrm{m}$ against $249 \mathrm{~m}$ ).

\section{Conclusion}

Meteorological modelling of the PBL over Greater Paris is performed using the WRF model for the period from 6 to 27 May 2005. As modelled meteorological data in the PBL have previously shown to be very sensitive to the PBL scheme, simulations were performed with various PBL schemes. Meteorological data obtained with the ACM2, MYJ, MYNN and YSU PBL schemes were compared to observations at various meteorological stations around Paris and its suburbs.

For air temperature, the errors of the modelled values are in the range of the errors obtained in previous studies and the MYNN scheme performs slightly better than others. However, the amplitudes of the diurnal cycle of the temperature are underestimated, particularly during daytime; and the underestimations tend to increase with altitude. Wind speeds are overestimated, particularly near the ground and the overestimations decrease with altitude. The YSU and the MYNN schemes perform better than the others.

For humidity, the modelled values are in good agreement with the observed values for the four PBL schemes, although relative humidity tends to be overestimated. The YSU and the MYNN schemes perform better for the relative humidity at the ground station and the specific humidity of radiosonde profiles, as well.

Larger differences between the simulations are obtained for the PBL height. The YSU and the MYJ schemes overestimate the PBL height while the ACM2 and the MYNN schemes underestimate the PBL height during nighttime. Mean PBL heights are also significantly different among them. The YSU scheme performs better than the others (maximum difference: $77 \%)$.

Including the UCM and the CORINE land-use data produces more realistic modelled meteorological fields. Improvements in the temperature and the specific humidity modelling using UCM-CORINE are low, but the modelling of the wind speed, the relative humidity and the PBL height is significantly improved using UCM-CORINE. In particular, modelled PBL heights with the MYNN scheme during nighttime are strongly influenced by UCM-CORINE (200\%). 
Influences of using the UCM and the CORINE land-use data on the modelled meteorological fields are greater than those using different PBL schemes, while the latter are greater for the upper air temperatures (above $40 \mathrm{~m}$ ) and the PBL heights estimated using radiosonde profiles at Trappes. Compared to the PBL heights observed by lidar measurements, the influences of using different PBL schemes at Palaiseau are more important than those of using the UCM and the CORINE land-use data, while the latter are more important at the centre of Paris. Our results show that the use of a urban canopy model is crucial for meteorological and air quality modelling over the centre of Paris. Further work should be devoted to the study of uncertainties in the UCM, for example, by using a multi-layer model. Multiple urban land-use categories (e.g., high intensity, medium intensity, and low intensity) should also be used. Multiple urban land-use categories are available in the CORINE land-use data, and should be mapped to a data type that can be used in the WRF model. Further work will also focus on evaluating the impact of the meteorological modelling on pollutant concentrations $\left(\mathrm{O}_{3}, \mathrm{NO}_{2}, \mathrm{PM}\right)$ within the PBL.

Acknowledgments The authors acknowledge Yang Zhang, North Carolina State University, for helpful discussions on the WRF simulation. Thanks are also due to Philippe Beguinel, CEA Saclay DSM/Sac/UPSE/SPR mesures métórologiques for providing measurement data; to Denis Fourgassié, Météo-France CIDM ParisMontsouris for providing meteorological fields at the Eiffel Tower; to Sylvain Dupont, US NCAR/MMM, for providing Fortran code for the urban model; to Delia Arnold, University of natural resources and life sciences in Vienna, for providing Fortran code for the CORINE land-use conversion; to Song-You Hong, Yonsei University in Seoul, for providing Fortran code for the YSU PBL parametrization. We also thank SIRTA for providing the meteorological fields. Our colleagues Victor Winiarek and Jérôme Drevet helped us with the WRF configuration and geographical information system (GIS) data usage, respectively. Helpful advice about meteorological data analysis was given by Luc Musson Genon, Bertrand Carissimo and Eric Dupont. Finally, we thank Christian Seigneur for helpful discussions and advice on the manuscript.

Open Access This article is distributed under the terms of the Creative Commons Attribution License which permits any use, distribution, and reproduction in any medium, provided the original author(s) and the source are credited.

\section{References}

Allen L, Lindberg F, Grimmond CSB (2011) Global to city scale urban anthropogenic heat flux: model and variability. Int J Climatol 31(13):1990-2005

Arnold D, Schicker I, Seibert P (2010) High-resolution atmospheric modelling in complex terrain for future climate simulations (HiRmod). VSC report 2010. http://www.boku.ac.at/met/envmet/hirmod.html

Berg LK, Zhong S (2005) Sensitivity of MM5-simulated boundary layer characteristics to turbulence parameterizations. J Appl Meteorol 44:1467-1483

Borge R, Alexandrov V, Josedelvas J, Lumbreras J, Rodrguez E (2008) A comprehensive sensitivity analysis of the WRF model for air quality applications over the Iberian Peninsula. Atmos Environ 42(37):8560-8574

Brooks IM (2003) Finding boundary layer top: application of a wavelet covariance transform to lidar backscatter profiles. J Atmos Ocean Technol 20(8):1092-1105

Chazette P, Sanak J, Dulac F (2007) New approach for aerosol profiling with a lidar onboard an ultralight aircraft: application to the African monsoon multidisciplinary analysis. Environ Sci Technol 41(24):83358341

Chen F, Dudhia J (2001) Coupling an advanced land surface-hydrology model with the Penn State-NCAR MM5 modeling system. Part I : Model implementation and sensitivity. Mon Weather Rev 129:569-585

Chen F, Kusaka H, Bornstein R, Ching J, Grimmond CSB, Grossman-Clarke S, Loridan T, Manning KW, Martilli A, Miao S, Sailor D, Salamanca FP, Taha H, Tewari M, Wang X, Wyszogrodzki AA, Zhang C (2011) The integrated WRF/urban modeling system: development, evaluation, and applications to urban environmental problems. Int J Climatol 31(2):479-492

Chou MD, Suarez MJ (1994) An efficient thermal infrared radiation parameterization for use in general circulation models. Technical report series on global modeling and data assimilation 3:85. http://archive. org/details/nasa_techdoc_19950009331 
Coindreau O, Hourdin F, Haeffelin M, Mathieu A, Rio C (2007) Assessment of physical parameterizations using a global climate model with stretchable grid and nudging. Mon Weather Rev 135:1474-1489

Dandou A, Tombrou M, Akylas E, Soulakellis N, Bossioli E (2005) Development and evaluation of an urban parameterization scheme in the Penn State/NCAR Mesoscale Model (MM5). J Geophys Res 110:D10102

Dupont S, Otte TL, Ching JKS (2004) Simulation of meteorological fields within and above urban and rural canopies with a mesoscale model. Boundary-Layer Meteorol 113:111-158

Fan H, Sailor DJ (2005) Modeling the impacts of anthropogenic heating on the urban climate of Philadelphia: a comparison of implementations in two PBL schemes. Atmos Environ 39(1):73-84

Flagg DD, Taylor PA (2011) Sensitivity of mesoscale model urban boundary layer meteorology to the scale of urban representation. Atmos Chem Phys 11(6):2951-2972

Flamant C, Pelon J, Flamant PH, Durand P (1997) Lidar determination of the entrainment zone thickness at the top of the unstable marine atmospheric boundary layer. Boundary-Layer Meteorol 83:247-284

Grell GA, Devenyi D (2002) A generalized approach to parameterizing convection combining ensemble and data assimilation techniques. Geophys Res Lett 29(14):38.1-38.4

Grossman-Clarke S, Zehnder JA, Loridan T, Grimmond CSB (2010) Contribution of land use changes to near-surface air temperatures during recent summer extreme heat events in the Phoenix metropolitan area. J Appl Meteorol Climatol 49:1649-1664

Haeffelin M, Barths L, Bock O, Boitel C, Bony S, Bouniol D, Chepfer H, Chiriaco M, Cuesta J, Delano J, Drobinski P, Dufresne JL, Flamant C, Grall M, Hodzic A, Hourdin F, Lapouge F, Lematre Y, Mathieu A, Morille Y, Naud C, Nol V, O'Hirok W, Pelon J, Pietras C, Protat A, Romand B, Scialom G, Vautard R (2005) SIRTA, a ground-based atmospheric observatory for cloud and aerosol research. Ann Geophys 23(2):253-275

Han Z, Ueda H, An J (2008) Evaluation and intercomparison of meteorological predictions by five MM5-PBL parameterizations in combination with three land-surface models. Atmos Environ 42(2):233-249

Holtslag AAM, Meijgaard E, Rooy WC (1995) A comparison of boundary layer diffusion schemes in unstable conditions over land. Boundary-Layer Meteorol 76:69-95

Hong SY, Pan HL (1996) Nonlocal boundary layer vertical diffusion in a medium-range forecast model. Mon Weather Rev 124(10):2322-2339

Hong SY, Noh Y, Dudhia J (2006) A new vertical diffusion package with an explicit treatment of entrainment processes. Mon Weather Rev 134(9):2318-2341

Hourdin F, Musat I, Bony S, Braconnot P, Codron F, Dufresne JL, Fairhead L, Filiberti MA, Friedlingstein P, Grandpeix JY, Krinner G, Levan P, Li ZX, Lott F (2006) The LMDZ4 general circulation model: climate performance and sensitivity to parametrized physics with emphasis on tropical convection. Clim Dyn 27:787-813

Hu XM, Nielsen-Gammon JW, Zhang F (2010) Evaluation of three planetary boundary layer schemes in the WRF model. J Appl Meteorol Climatol 49(9):1831-1844

Janjić ZI (1990) The step-mountain coordinate: physical package. Mon Weather Rev 118(7):1429

Janjić ZI (2001) Nonsingular implementation of the Mellor-Yamada level 2.5 scheme in the NCEP meso model. National Centers for Environmental Prediction, Office Note 437, 61 pp. http://www.emc.ncep. noaa.gov/officenotes/newernotes/on437.pdf

Kessler E (1969) On the distribution and continuity of water substance in atmospheric circulation. Meteorol Monogr 10:1-84

Kim Y, Fu JS, Miller TL (2010) Improving ozone modeling in complex terrain at a fine grid resolution: part I examination of analysis nudging and all PBL schemes associated with LSMs in meteorological model. Atmos Environ 44(4):523-532

Korsakissok I, Mallet V (2010) Development and application of a reactive plume-in-grid model: evaluation over Greater Paris. Atmos Chem Phys 10(18):8917-8931

Kusaka H, Kimura F (2004) Thermal effects of urban canyon structure on the nocturnal heat island: numerical experiment using a mesoscale model coupled with an urban canopy model. J Appl Meteorol 43:1899-1910

Kusaka H, Kondo H, Kikegawa Y, Kimura F (2001) A simple single-layer urban canopy model for atmospheric models: comparison with multi-layer and slab models. Boundary-Layer Meteorol 101:329-358

Lee SH, Kim SW, Angevine W, Bianco L, McKeen S, Senff C, Trainer M, Tucker S, Zamora R (2010) Evaluation of urban surface parameterizations in the WRF model using measurements during the Texas Air Quality Study 2006 field campaign. Atmos Chem Phys 11:2127-2143

Lemonsu A, Masson V (2002) Simulation of a summer urban breeze over Paris. Boundary-Layer Meteorol 104:463-490

Lin CY, Chen F, Huang J, Chen WC, Liou YA, Chen WN, Liu SC (2008) Urban heat island effect and its impact on boundary layer development and land-sea circulation over northern Taiwan. Atmos Environ 42(22):5635-5649 
Loridan T, Grimmond C (2012) Multi-site evaluation of an urban land-surface model: intra-urban heterogeneity, seasonality and parameter complexity requirements. Q J R Meteorol Soc 138(665):1094-1113

Loridan T, Grimmond CSB, Grossman-Clarke S, Chen F, Tewari M, Manning K, Martilli A, Kusaka H, Best M (2010) Trade-offs and responsiveness of the single-layer urban canopy parametrization in WRF: an offline evaluation using the MOSCEM optimization algorithm and field observations. Q J R Meteorol Soc 136(649):997-1019

Macdonald R, Griffiths R, Hall D (1998) An improved method for the estimation of surface roughness of obstacle arrays. Atmos Environ 32(11):1857-1864

Mallet V, Sportisse B (2006) Uncertainty in a chemistry-transport model due to physical parameterizations and numerical approximations: an ensemble approach applied to ozone modeling. J Geophys Res 111:D01302

Martilli A, Clappier A, Rotach MW (2002) An urban surface exchange parameterisation for mesoscale models. Boundary-Layer Meteorol 104:261-304

Mellor GL, Yamada T (1974) A hierarchy of turbulence closure models for planetary boundary layers. J Atmos Sci 31:1791-1806

Menut L, Flamant C, Pelon J, Flamant PH (1999) Urban boundary-layer height determination from lidar measurements over the Paris area. Appl Opt 38(6):945-954

Météo-France (2005) Bulletin climatologique mensuel, 75 Paris et petite couronne, Mai 2005. https://public. meteofrance.com/

Miao S, Chen F, Lemone MA, Tewari M, Li Q, Wang Y (2009) An observational and modeling study of characteristics of urban heat island and boundary layer structures in Beijing. J Appl Meteorol Climatol 48:484-501

Mlawer EJ, Taubman SJ, Brown PD, Iacono MJ, Clough SA (1997) Radiative transfer for inhomogeneous atmospheres: RRTM, a validated correlated-k model for the longwave. J Geophys Res 102(D14):1666316682

Moeng CH, Dudhia J, Klemp J, Sullivan P (2007) Examining two-way grid nesting for large eddy simulation of the PBL using the WRF model. Mon Weather Rev 135(6):2295-2311

Nakanishi M, Niino H (2004) An improved Mellor Yamada Level-3 model with condensation physics: its design and verification. Boundary-Layer Meteorol 112:1-31

Nakanishi M, Niino H (2009) Development of an improved turbulence closure model for the atmospheric boundary layer. J Meteorol Soc Jpn 87(5):895-912

Oke TR (1987) Boundary layer climates, 2nd edn. Routledge, London, 435 pp

Oke TR (2006) Initial guidance to obtain representative meteorological observations at urban sites. WMO/TDNo. 1250 available at http://www.wmo.int/pages/prog/www/IMOP/publications/IOM-81/IOM-81-Urban MetObs.pdf

Olson JB, Brown JM (2009) A comparison of two Mellor-Yamada-based PBL schemes in simulating a hybrid barrier jet. In: 23rd Conference on weather analysis and forecasting/19th conference on numerical weather prediction, Omaha. http://ams.confex.com/ams/pdfpapers/154321.pdf

Otte TL, Lacser A, Dupont S, Ching JKS (2004) Implementation of an urban canopy parameterization in a mesoscale meteorological model. J Appl Meteorol 43:1648-1665

Pigeon G, Legain D, Durand P, Masson V (2007) Anthropogenic heat release in an old European agglomeration (Toulouse, France). Int J Climatol 27:1969-1981

Pineda N, Jorba O, Jorge J, Baldasano JM (2004) Using NOAA AVHRR and SPOT VGT data to estimate surface parameters: application to a mesoscale meteorological model. Int J Remote Sens 25(1):129-143

Pleim JE (2006) A simple, efficient solution of flux profile relationships in the atmospheric surface layer. J Appl Meteorol Climatol 45:341-347

Pleim JE (2007) A combined local and nonlocal closure model for the atmospheric boundary layer. Part I: Model description and testing. J Appl Meteorol Climatol 46(9):1383-1395

Pleim JE, Chang JS (1992) A non-local closure model for vertical mixing in the convective boundary layer. Atmos Environ 26A:965-981

Raut JC, Chazette P (2009) Assessment of vertically-resolved PM $_{10}$ from mobile lidar observations. Atmos Chem Phys 9(21):8617-8638

Roustan Y, Sartelet K, Tombette M, Debry É, Sportisse B (2010) Simulation of aerosols and gas-phase species over Europe with the Polyphemus system. Part II: Model sensitivity analysis for 2001. Atmos Environ 44(34):4219-4229

Roustan Y, Pausader M, Seigneur C (2011) Estimating the effect of on-road vehicle emission controls on future air quality in Paris, France. Atmos Environ 45(37):6828-6836

Royer P, Chazette P, Sartelet K, Zhang QJ, Beekmann M, Raut JC (2011) Comparison of lidar-derived PM 10 with regional modeling and ground-based observations in the frame of MEGAPOLI experiment. Atmos Chem Phys 11(20):10705-10726 
Sailor D, Lu L (2004) A top-down methodology for developing diurnal and seasonal anthropogenic heating profiles for urban areas. Atmos Environ 38(17):2737-2748

Salamanca F, Krpo A, Martilli A, Clappier A (2010) A new building energy model coupled with an urban canopy parameterization for urban climate simulations-part I. Formulation, verification, and sensitivity analysis of the model. Theor Appl Climatol 99:331-344

Salamanca F, Martilli A, Tewari M, Chen F (2011) A study of the urban boundary layer using different urban parameterizations and high-resolution urban canopy parameters with WRF. J Appl Meteorol Climatol 50:1107-1128

Sarkar A, De Ridder K (2011) The urban heat island intensity of Paris: a case study based on a simple urban surface parametrization. Boundary-Layer Meteorol 138:511-520

Sarrat C, Lemonsu A, Masson V, Guedalia D (2006) Impact of urban heat island on regional atmospheric pollution. Atmos Environ 40(10):1743-1758

Sciare J, d'Argouges O, Zhang QJ, Sarda-Estève R, Gaimoz C, Gros V, Beekmann M, Sanchez O (2010) Comparison between simulated and observed chemical composition of fine aerosols in Paris (France) during springtime: contribution of regional versus continental emissions. Atmos Chem Phys 10(24):11987-12004

Shin H, Hong SY (2011) Intercomparison of planetary boundary-layer parametrizations in the WRF model for a single day from CASES-99. Boundary-Layer Meteorol 139:261-281

Skamarock WC, Klemp JB, Dudhia J, Gill DO, Barker DM, Duda MG, Huang XY, Wang W, Powers JG (2008) A description of the Advanced Research WRF version 3. NCAR Technical note-475+STR, 113 pp. http://www.mmm.ucar.edu/wrf/users/docs/arw_v3.pdf

Srinivas C, Venkatesan R, Singh AB (2007) Sensitivity of mesoscale simulations of land-sea breeze to boundary layer turbulence parameterization. Atmos Environ 41(12):2534-2548

Steyn DG, Baldi M, Hoff RM (1999) The detection of mixed layer depth and entrainment zone thickness from lidar backscatter profiles. J Atmos Ocean Technol 16(7):953-959

Stull RB (1988) An introduction to boundary layer meteorology. Kluwer, Dordrecht, 666 pp

Svensson G, Holtslag A, Kumar V, Mauritsen T, Steeneveld G, Angevine W, Bazile E, Beljaars A, Bruijn E, Cheng A, Conangla L, Cuxart J, Ek M, Falk M, Freedman F, Kitagawa H, Larson V, Lock A, Mailhot J, Masson V, Park S, Pleim J, Sderberg S, Weng W, Zampieri M (2011) Evaluation of the diurnal cycle in the atmospheric boundary layer over land as represented by a variety of single-column models: the second GABLS experiment. Boundary-Layer Meteorol 140:177-206

Tombette M, Sportisse B (2007) Aerosol modeling at a regional scale: model-to-data comparison and sensitivity analysis over Greater Paris. Atmos Environ 41(33):6941-6950

Vautard R, Builtjes P, Thunis P, Cuvelier C, Bedogni M, Bessagnet B, Honoré C, Moussiopoulos N, Pirovano G, Schaap M, Stern R, Tarrason L, Wind P (2007) Evaluation and intercomparison of ozone and PM 10 simulations by several chemistry transport models over four European cities within the CityDelta project. Atmos Environ 41(1):173-188

Wang ZH, Bou-Zeid E, Au SK, Smith JA (2011) Analyzing the sensitivity of WRF's single-layer urban canopy model to parameter uncertainty using advanced Monte Carlo simulation. J Appl Meteorol Climatol 50:1795-1814

Zhang D, Anthes RA (1982) A high-resolution model of the planetary boundary layer-sensitivity tests and comparisons with SESAME-79 data. J Appl Meteorol 21:1594-1609 